\title{
Detailed Mechanistic Studies on Palladium Catalyzed Selective C-H Olefination with Aliphatic Alkenes: A Significant Influence of Proton Shuttling
}

\author{
Arghya Deb, ${ }^{\dagger}$ AvijitHazra, ${ }^{\dagger}$ Qian Peng, $,{ }^{\S}, *$ Robert S. Paton, ${ }^{\S *}$ DebabrataMaiti ${ }^{\dagger *}$ \\ ${ }^{\dagger}$ Department of Chemistry, Indian Institute of Technology Bombay, Powai, Mumbai 400076, India

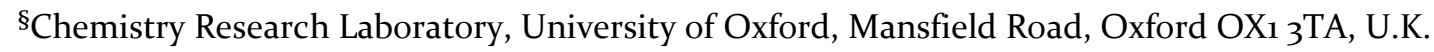 \\ \#State Key Laboratory of Elemento-Organic Chemistry,Nankai University, Tianjin 300o71, P.R. China
}

\begin{abstract}
Directing group assisted regioselective $\mathrm{C}-\mathrm{H}$ olefination with electronically biased olefins are well studied. However, the incorporation of unactivated olefins has remained largely unsuccessful. A proper mechanistic understanding of olefination involving unactivated alkenes is therefore essential for enhancing their usage in future. In this article, detailed experimental and computational mechanistic studies on palladium catalyzed $\mathrm{C}-\mathrm{H}$ olefination with unactivated, aliphatic alkenes are described. The isolation of $\mathrm{Pd}(\mathrm{II})$ intermediates are shown to be effective for elucidating the elementary steps involved in catalytic olefination. Reaction rate and order determination, control experiments, isotopic labeling studies and Hammett analysis have been used to understand the reaction mechanism. The results from these experimental studies implicate $\beta$-hydride elimination as the rate-determining step and that a mechanistic switch occurs between cationic and neutral pathway. Computational studies support this interpretation of the experimental evidence and are used to uncover the origins of selectivity.
\end{abstract}

The significant reactivity of organopalladium intermediates $[\mathrm{R}-\mathrm{Pd}(\mathrm{II})]$ has resulted in the discovery of a diverse array of carbon-carbon $^{1}$ and carbon-heteroatom ${ }^{2}$ bond forming reactions during the last half-century. Exploiting this intermediate, the Mizoroki-Heck reaction, 3 coupling aryl halides ( $\mathrm{R}-\mathrm{X})$ and olefins to produce olefinated arenes, has contributed significantly to the advancement of modern synthetic chemistry. To substitute the use of an expensive prefunctionalized coupling partner (e.g. aryl halides, R-X), successive developments in $\mathrm{Pd}(0) / \mathrm{Pd}$ (II) redox chemistry have led to the use of unactivated $\mathrm{C}-\mathrm{H}$ bonds ${ }^{4}$ as a synthon in arene olefination chemistry (Fujiwara Moritani reaction). 5 The ubiquity of $\mathrm{C}-\mathrm{H}$ bonds in naturally occurring organic compounds make this approach synthetically useful, while also presenting a challenge to control site-selectivity.

Over the last two decades, significant progress in $\mathrm{C}-\mathrm{H}$ bond olefination has been achieved by the use of different transition metals $s^{6-7}$ along with palladium. ${ }^{8}$ In order to achieve predictable site-selectivity for the activation of carbogenic substrates containing multiple $\mathrm{C}-\mathrm{H}$ bonds, the contribution of tethered directing groups has played a prominent role. 9 These directing groups direct the metalcatalyzed activation of a proximal $\mathrm{C}-\mathrm{H}$ bond to form a metallacycle intermediate. The coordination of the catalyst renders olefination highly site-selective and kinetically fast. In addition to ortho-selective $\mathrm{C}-\mathrm{H}$ activation, tuning the nature of the directing group has enabled the development of meta-selective $\mathrm{C}-\mathrm{H}$ olefinations. ${ }^{10}$ Recently the palladiumcatalyzed oxidative coupling of alkenes has been accomplished through para-selective $\mathrm{C}($ aryl $)-\mathrm{H}$ bond activation, which has opened new avenues for diversifying simple structural motifs."

Although these examples show the significant advances made in the field, olefination has traditionally been restricted to electronically biased olefins such as acrylates and styrenes (Scheme 1) ${ }^{6-8}$ Despite significant efforts, very little reactivity and regioisomeric mixtures have been observed with unactivated olefins..$^{\mathrm{k},}$ 8h $\mathrm{A}$ detailed understanding of selectivity for $\mathrm{C}-\mathrm{H}$ olefination reactions with unactivated alkenes $^{12}$ both in terms of arene regiochemistry and alkene stereochemistry is, therefore, fundamental to circumvent the current limitations.

Scheme 1. Directed olefination with biased and unactivated olefins

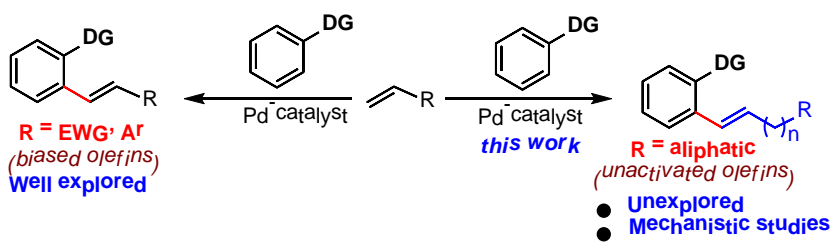

In 2014, we reported the palladium catalyzed $\mathrm{C}-\mathrm{H}$ olefination in which completely unbiased and unactivated aliphatic olefins were incorporated in a linear fashion with high stereo- and regioselectivity to the aryl $\mathrm{C}-\mathrm{H}$ bond of the 8-aminoquinoline phenylacetamide (Scheme 2).13 This method employs palladium acetate along with a racemic $1, \mathbf{1}^{\prime}-$ binaphthyl-2,2'-diamine (rac-BINAM) ligand in the presence of a mild base, sodium bicarbonate $\left(\mathrm{NaHCO}_{3}\right)$. Benzoquinone and an oxygen atmosphere were used as oxidants when the 8-aminoquinolinamide of phenyl acetic acid was reacted with aliphatic olefins in dichloroethane. The generality of this position-selective alkenylation protocol was demonstrated by accessing exemplary sets of mono- and di-alkenylated compounds, which represent a class of new chemical entities. 
Scheme 2. Ortho- $\mathrm{C}-\mathrm{H}$ bond olefination with 1-octene

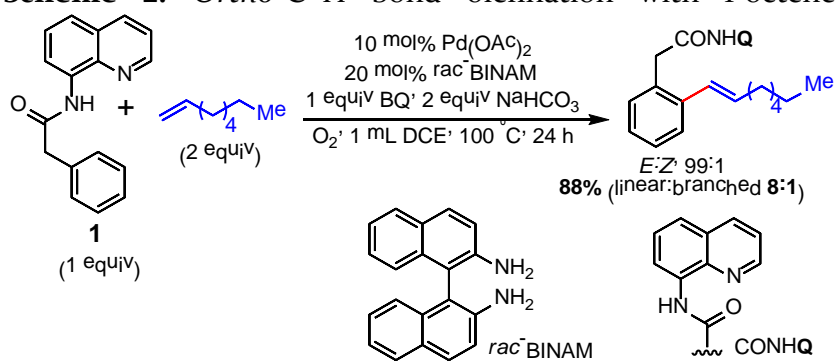

We report the results of detailed experimental investigations using rate and order determination, complete characterization of intermediate organometallic species, labeling studies, controlled experiments and Hammett analysis to understand the mechanism of this regioselective olefination with unactivated alkenes. An accompanying computational analysis has played a crucial role in understanding the origin of selectivity in the olefination reaction with unactivated alkenes and the role of BINAM in this catalytic system.

\section{RESULTS AND DISCUSSION}

Isolation and characterization of an arylpalladium(II) intermediate. In order to begin a mechanistic investigation, we focused on preparation of the arylpalladium reactive intermediate proposed to be involved prior to olefination. Stoichiometric $\mathrm{Pd}(\mathrm{OAc})_{2}$ was reacted with a number of electronically different phenylacetamides of 8aminoquinoline in acetonitrile at $65{ }^{\circ} \mathrm{C}$. To our delight, the resulting organopalladium species could be crystalized and a distorted square planar $\mathrm{Pd}(\mathrm{II})$ geometry for each of the acetamides is established by the X-ray structures (Figure 1$)^{14}$. The stability of these aryl palladium intermediates is attributable to the rigid coordination of the metal by the quinoline nitrogen atom and the formation of a sixmembered palladacycle from ortho- $\mathrm{C}-\mathrm{H}$ activation of the phenyl group.
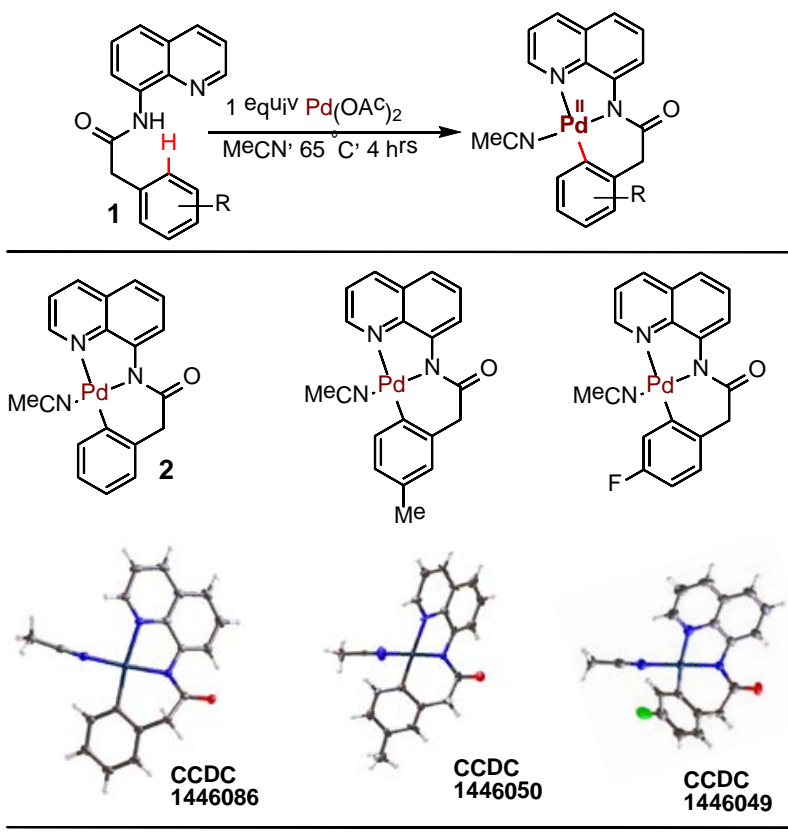

Figure 1. X-ray structures of arylpalladium intermediates
The formation of these organopalladium intermediates was investigated computationally using density functional theory (DFT). ${ }^{16}$ Geometry optimizations were performed at the (dispersion-corrected) $\omega \mathrm{B} 97 \mathrm{XD} / 6-31 \mathrm{G}^{*} / \mathrm{Lanl} 2 \mathrm{DZ}$ level of

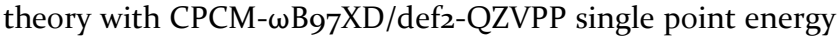
calculations. ${ }^{16}$ The $\omega$ B $97 \mathrm{XD}$ energy profile was compared with the results of Mo6/def2-QZVPP single point energy calculations and gave comparable results. ${ }^{16}$ This methodology has been previously applied to the study of $\mathrm{Pd}(\mathrm{II})$ catalysis to give good agreement with experimental results. ${ }^{17}$ All optimized species were verified as either minima or transition structures(TSs) by the presence of zero or a single imaginary vibrational frequency, respectively. Quasiharmonic Gibbs free energies ${ }^{18}$ were evaluated at the reaction temperature using vibrational frequencies: rigid rotor harmonic oscillator (RRHO) vibrational entropies were used above $100 \mathrm{~cm}^{-1}$ while a free rotor description was used below this value, as described by Grimme. ${ }^{19}$ Molecular graphics were produced with Cylview. ${ }^{20}$

The computed pathway for palladacycle formation is shown in Figure 2. Two separate concerted metalationdeprotonation (CMD) steps, assisted by the acetate ligands, were identified. ${ }^{21}$ These transition structures show the characteristics of Ambiphilic Metal-Ligand Assistance (AMLA), as first described by Davies and Macgregor, ${ }^{21 a} \mathrm{Pd}$ interacting with the breaking $\mathrm{C}-\mathrm{H} / \mathrm{N}-\mathrm{H}$ bond and the acetate acting as a basic co-ligand. In studying the effect of the anionic ligand and the monomer/dimer equilbrium in $\operatorname{Pd}(\mathrm{II})$ catalysis, Sanford and Schoenebeck found no mechanistic difference between acetate or carbonate in $\mathrm{C}-\mathrm{H}$ activation steps ${ }^{22 a}$, so we focus our attention on the monomeric acetate complex. Bidentate coordination of $\mathrm{Pd}(\mathrm{OAc})_{2}$ by the substrate's two $\mathrm{N}$ atoms is favorable by $\mathbf{2 . 1}$ $\mathrm{kcal} / \mathrm{mol}$. Activation of the amide $\mathrm{N}-\mathrm{H}$ bond is facile, via TS1 with an activation barrier of $5.3 \mathrm{kcal} / \mathrm{mol}$, forming the most stable intermediate Int-2. Secondly, ortho-palladation of the phenyl group has a computed activation barrier of 16.8 $\mathrm{kcal} / \mathrm{mol}$ (readily accessible via TS2) to form the palladacycleInt-3. ${ }^{22 \mathrm{~b}-22 \mathrm{f}} \mathrm{C}-\mathrm{H}$ activation is predicted to be reversible since the barrier in the reverse direction is lower by $5.4 \mathrm{kcal} / \mathrm{mol}$. However, we were able to account for the stability of the isolated palladacycle by taking into account acetonitrile coordination. Ligand substitution of $\mathrm{AcOH}$ by $\mathrm{MeCN}$ is exergonic by $6.2 \mathrm{kcal} /$ moland forms the most stable species Int-4 since $\mathrm{MeCN}$ is present in large excess this process will be even more favorable than indicated by the standard state Gibbs energy computed at $1 \mathrm{~mol} / \mathrm{l}$. 


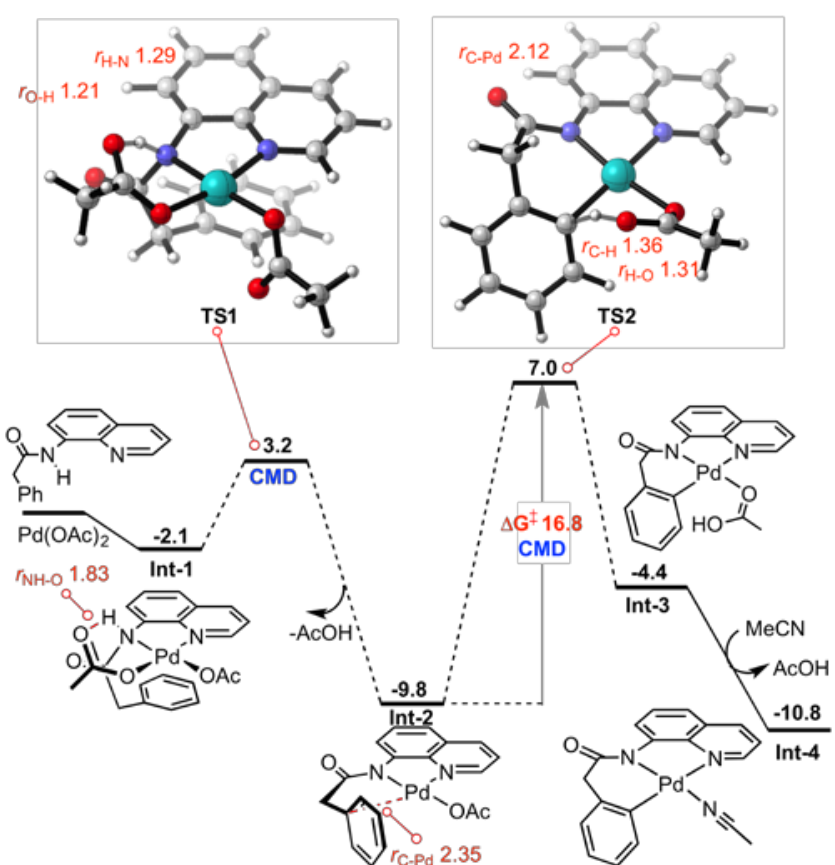

Figure 2. DFT-computed steps for ortho-palladation of $\mathbf{1}$. CPCM- $\omega$ B97XD/def2-QZVPP// $\omega$-B97XD/6-

${ }_{31} \mathrm{G}^{*} /$ Lanl2DZGibbs energies in $\mathrm{kcal} / \mathrm{mol}$; Selected distances shown in Å. Unless otherwise stated all Figures adopt this convention.

To probe the mechanism of olefination with unactivated olefins, we first tested the chemical and kinetic competence of arylpalladium species 2 (Figure 3). Phenylacetamide was subjected to standard reaction conditions replacing catalytic $\mathrm{Pd}(\mathrm{OAc})_{2}$ with the isolated arylpalladium species 2 (10 $\mathrm{mol} \%)$. The olefinated product was isolated in $84 \%$ yield as compared to $88 \%$ under the standard reaction conditions with 1-octene. Intermediate 2 was then subjected to the reaction conditions and we found that the rate of the reaction is similar to that of $\mathrm{Pd}(\mathrm{OAc})_{2}$ and amide (Figure 3). Therefore, intermediate $\mathbf{2}$ is kinetically competent. Moreover, this result implies that $\mathbf{2}$ is capable of rapid palladium transfer to another substrate molecule for the $\mathrm{C}-\mathrm{H}$ activation step.

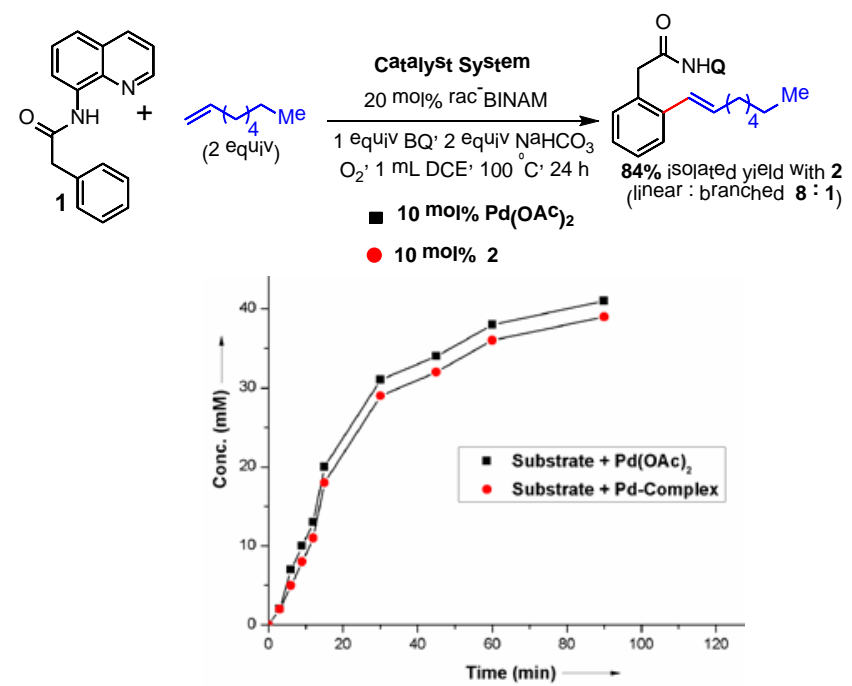

Figure 3. Kinetic competence of arylpalladium species
NMR studies of carbopalladation with the catalytically competent arylpalladium (II) intermediate. Next, we investigated the reaction of olefin with complex 2 . The reaction was probed in an NMR tube using $\mathrm{CDCl}_{3}$ solvent (Figure 4). In order to observe reactivity at room temperature and also to get clear upfield signals, we used tert-butyl acrylate (an activated alkene) instead of 1-octene. The sharp peaks in the 5.5-6.5 ppm region of the ${ }^{1} \mathrm{H}$ NMR spectrum correspond to the olefinic double bond of free acrylate. After just 5 minutes following the addition of arylpalladium complex $\mathbf{2}$, significant broadening of these signals was observed, attributable to the coordination of Pd(II) by the olefin to form species 3. This is also evident from the ${ }^{13 C}$ NMR where two additional peaks were observed in addition to the original acrylate ${ }^{13 C}$ peaks in a comparatively upfield position. ${ }^{14}$ Such observations can be attributed to an increase in aliphatic character of the olefinic carbon atoms due to the co-ordination with palladium.

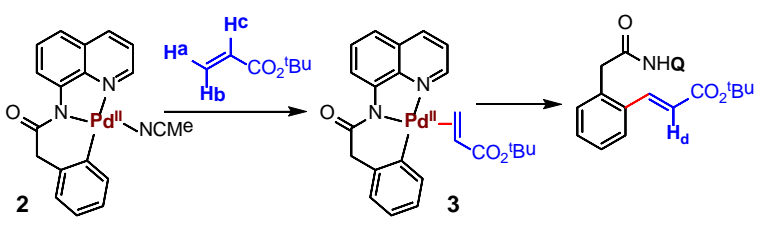

olefinic region of acrylate

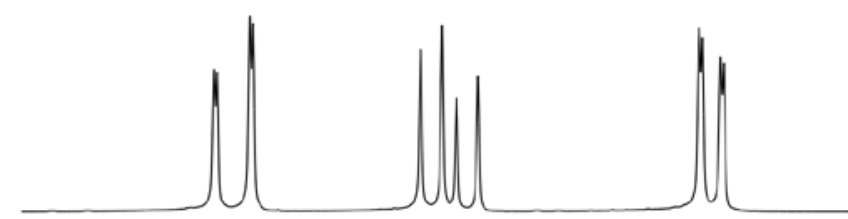

5 minutes after addition of complex 2 with acrylate

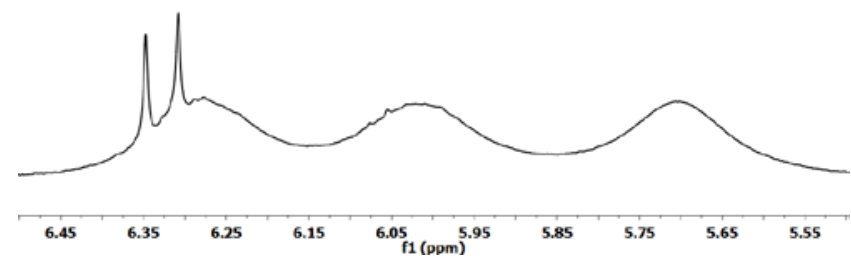

Figure 4. Broadening of the ${ }^{1} \mathrm{H}$ NMR olefinic region due to coordination of $\mathrm{Pd}$ 


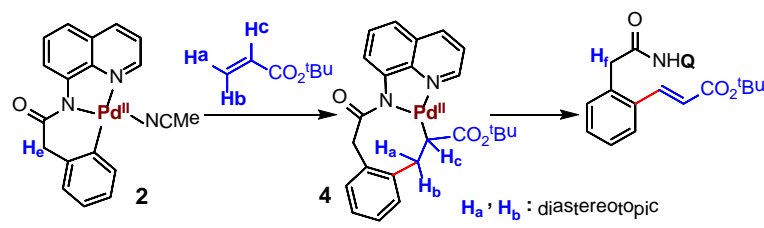

NMR of acrylate
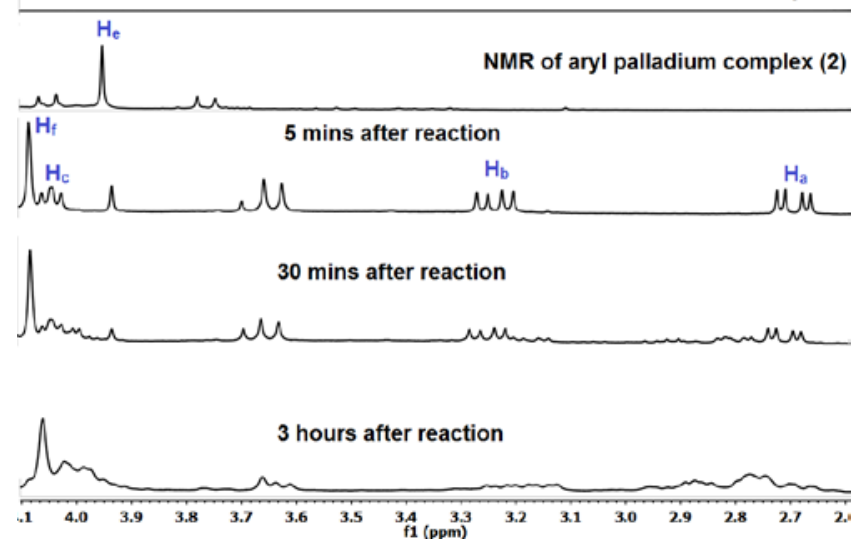

Figure 5. Detection of carbopalladated intermediates

For the carbopalladation of $\mathbf{2}$, the $\beta$-migratory insertion of palladium across the olefinic double bond was observed with respect to time by ${ }^{1} \mathrm{H}$ NMR (Figure $5,2-4 \mathrm{ppm}$ ). Distinct aliphatic peaks corresponding to $\mathrm{H}_{\mathrm{c}}$ and diastereotopic $\mathrm{H}_{\mathrm{a}} / \mathrm{H}_{\mathrm{b}}$ were observed due to the formation of new intermediate arylpalladium species $\mathbf{4}$, following the formation of the $\mathrm{Pd}(\mathrm{II})$ :olefin complex. ${ }^{23}$ Thus, it is possible to observe the disappearance of characteristic peaks belonging to intermediate 3 and the appearance of the product of olefin-insertion with respect to time. This indicates that the synthesized pre-catalyst $\mathbf{2}$ is a viable intermediate for olefination. However we failed to detect any characteristic intermediate ${ }^{1} \mathrm{H}$ NMR signals when this experiment was carried out with 1-octene at room temperature.

Role of different components for olefination with an unactivatedalkene. The success of this palladium-catalyzed olefination was dependent on the identity of the directing group as it plays an extremely important role in metal coordination. Strongly coordinating 8 -aminoquinoline ${ }^{24}$ was experimentally found as the best directing group for promoting the reaction. Notably, 8-hydroxyquinoline and $\mathrm{N}$ methyl 8-aminoquinoline derived amides did not react. Other $s p^{2}-s p^{3}$ combination of nitrogen incorporated into the directing scaffold could not surpass 8-aminoquinoline in terms of yields and selectivity towards forming the linear product.

Scheme 3. Tethered directing group with variation of chain length

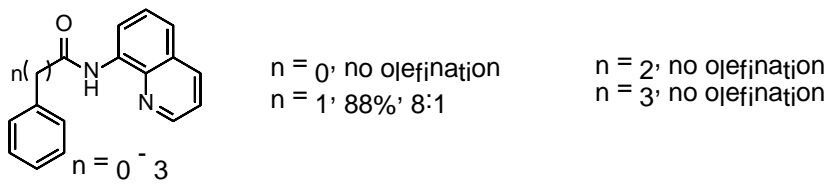

Encouraged by the olefination of arylacetic acid in presence of 8-aminoquinoline, we hypothesized that similar olefination could be achieved using other highly important scaffolds. Surprisingly, benzoic acid and hydrocinnamic acid derived amides formed with 8-aminoquinoline failed to generate the expected olefination product (Scheme 3). Evidently, in addition to strong coordination by the directing group, the stability of the 6-membered palladacycle (see Xray, Figure 1) also plays a key-role for this $\mathrm{C}-\mathrm{H}$ olefination with unactivated alkenes. The crystallographically characterized (CCDC 1518907) five membered metallacycle failed to deliver the desired olefinated product under the standard reaction condition (Scheme 4). Stability of the five membered palladacyle as well as the generation of seven membered intermediate upon olefin insertion may be the reason for the unsuccessful olefination.

Scheme 4. Olefination with 5-membered metallacycle
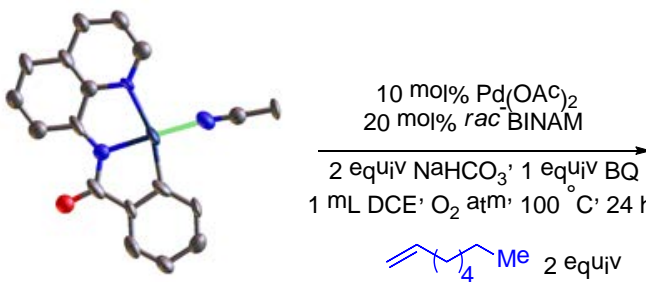

No Product

CCDC 1518907

1 equiv

Kinetic studies were performed to investigate the role of individual components in the reaction medium. It is worth noting that the reaction works best in presence of a base $\left(\mathrm{NaHCO}_{3}\right)$ with BQ as the oxidant, and rac-BINAM as the ligand (Scheme 2). We carried out parallel reactions and quenched them at regular intervals. Yield of the olefinated product from crude reaction mixtures was determined by gas chromatography using $n$-decane as the internal standard. Four sets of kinetic studies have been performed under the following conditions: standard protocol (set 1), without racBINAM (set 2), without rac-BINAM and benzoquinone (set 3 ), without rac-BINAM and sodium bicarbonate (set 4). The results obtained are shown in Figure 6.

Applying the standard protocol (set 1), after 10 mins of reaction time, the concentration of product is almost double that obtained under the other sets of conditions (sets 2-4). This clearly indicates a more sluggish reaction in the absence of any components of Scheme 2. Without rac-BINAM and benzoquinone (set 3), the phenyl acetamideis capable of forming olefinated product albeit in lower yield and selectivity.

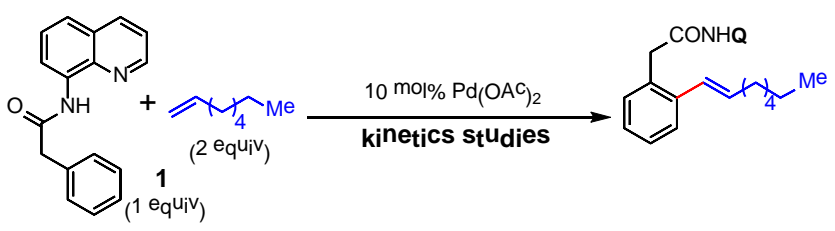




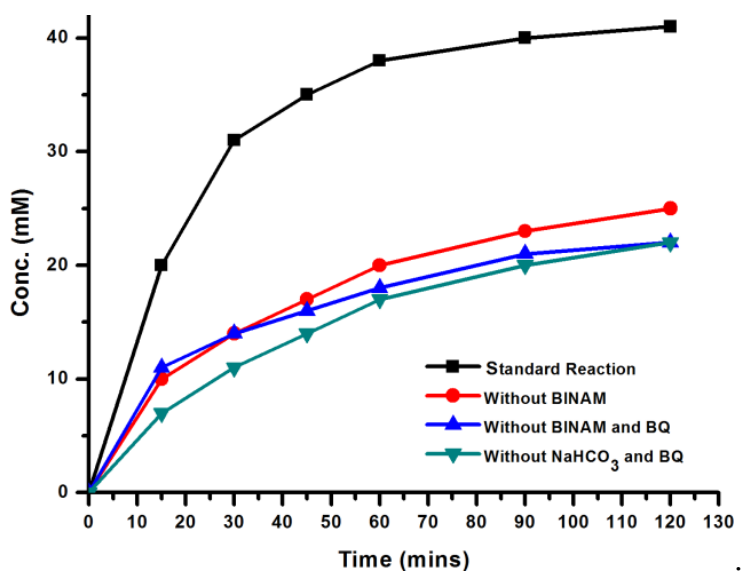

Figure 6. Kinetic studies to probe the role of individual components

According to literature precedence, ligand-free condition may lead to very poor yield of olefinated product

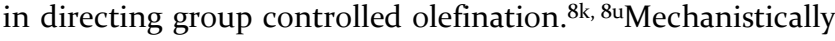
our result is in direct contrast with the earlier reported results of ligand enabled $\mathrm{C}-\mathrm{H}$ olefination reactions employing monodentate directing scaffolds and activated olefins. ${ }^{8}$

The role of base in the reaction was interrogated when the arylpalladium complex $\mathbf{2}$ was reacted with other phenylacetamide (Scheme 5). Formation of the aryl palladium complex 5 was observed when $\mathrm{NaHCO}_{3}$ was employed as the base. In absence of $\mathrm{NaHCO}_{3}$, we failed to detect the formation of complex 5 . These results confirm that palladacycle formation is readily reversible under the reaction conditions, as is suggested by computations of the forward and reverse barrier heights for the $\mathrm{N}-\mathrm{H}$ and $\mathrm{C}-\mathrm{H}$ activation steps (Figure 2 ).

Scheme 5. Probing base assisted reversible $\mathrm{C}-\mathrm{H}$ activation<smiles>O=C(Cc1ccc(O)cc1)Nc1cccc2cccnc12</smiles>
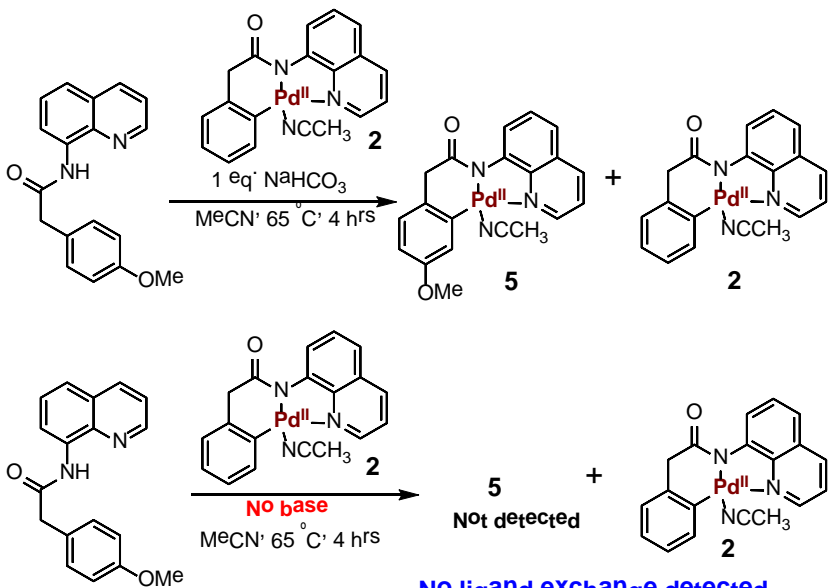

No ligand exchange detected

Scheme 6. Kinetic resolution experiment
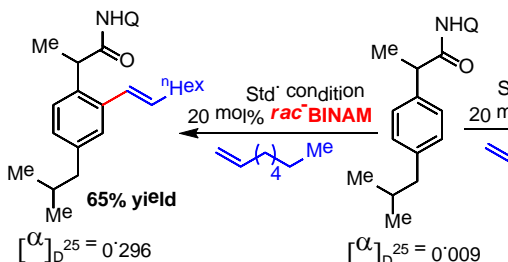

$\left[{ }^{\alpha}\right]_{D}{ }^{25}=0^{\prime} 009$
A kinetic resolution experiment has shed some light on the role of BINAM for the olefination reaction (Scheme 6). A racemic $N$-quinolinamide of Ibuprofen $\left([\alpha]_{\mathrm{D}}, 0.009\right)$ was found to give olefinated product $\left([\alpha]_{D},-1.2\right)$ when it was treated with (R)-BINAM ligand. The recovered starting material was also found to have induced chirality when the reaction was carried out with chiral (R)-BINAM ligand. Product obtained with rac-BINAM was found to have very low induced chirality $\left([\alpha]_{D},+0.296\right)$. Result of these experiments is indicating that BINAM is playing a crucial role by promoting the amide $N$-diastereomeric protonation.

Kinetic studies: reagent orders and isotoptic labeling. In order to establish the reaction rate, kinetic studies were performed to determine the order with respect to substrate and olefin. Sets of experiments were performed in which with either the concentration of amide or the concentration of olefin were maintained in large excess, alongside experiments using the standard reaction conditions. ${ }^{13}$ The yield of olefinated product was obtained from monitoring the crude reaction mixture and was plotted against reaction time (Figure 7). By calculating the initial slopes, a first order rate dependency with respect to phenylacetamide as well as 1octene was determined:

\section{$d[$ product $] / d t=k[\text { phenylacetamide }]^{1}$.[1-octene $]^{1}$}

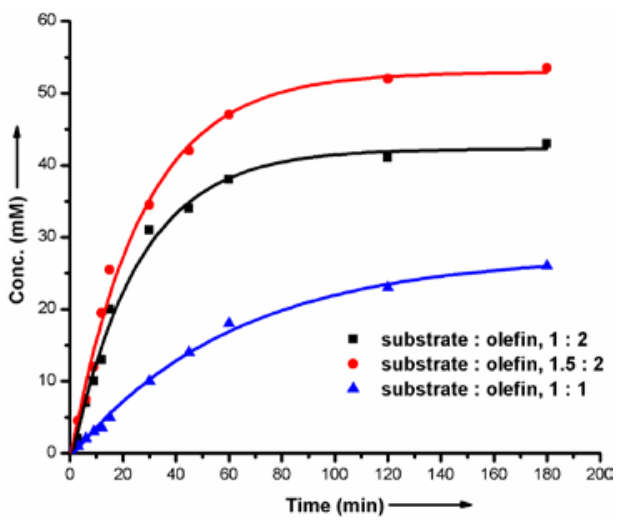

Figure 7. Rate and order dependency of $\mathrm{C}-\mathrm{H}$ olefination

The first order dependence on olefin revealed that the initial $\mathrm{C}-\mathrm{H}$ bond cleavage of the phenylacetamide is not ratelimiting for the overall reaction. This is consistent with our computational data, showing $\mathrm{C}-\mathrm{H}$ activation to be relatively facile (with an activation barrier of $16.8 \mathrm{kcal} / \mathrm{mol}$ ) and palladacycle formation as reversible, confirmed in crossover experiments (Scheme 5). A subsequent step involving the alkene must be turnover limiting. For further confirmation, we measured the intermolecular kinetic isotope effect (KIE) by preparing deuterium labeled phenyl acetamide of 8aminoquinoline. A gram-scale synthesis of deuteriated phenylacetamide $\left(\mathbf{D}_{\mathbf{5}}-\mathbf{1}\right)$ was carried out by reacting phenylacetamide (1) with $10 \mathrm{~mol} \% \mathrm{Pd}(\mathrm{OAc})_{2}$ and $\mathrm{D}_{4}-\mathrm{AcOH}$ at an elevated temperature of $100{ }^{\circ} \mathrm{C}$. The alkenylated product formation was monitored with respect to time by following the standard protocol for the $\mathbf{D}_{5} \mathbf{- 1}$ and 1-octene (Scheme 7 , Figure 8). The KIE was determined by comparing initial

Scheme 7. KIE experiment with labeled acetamide 

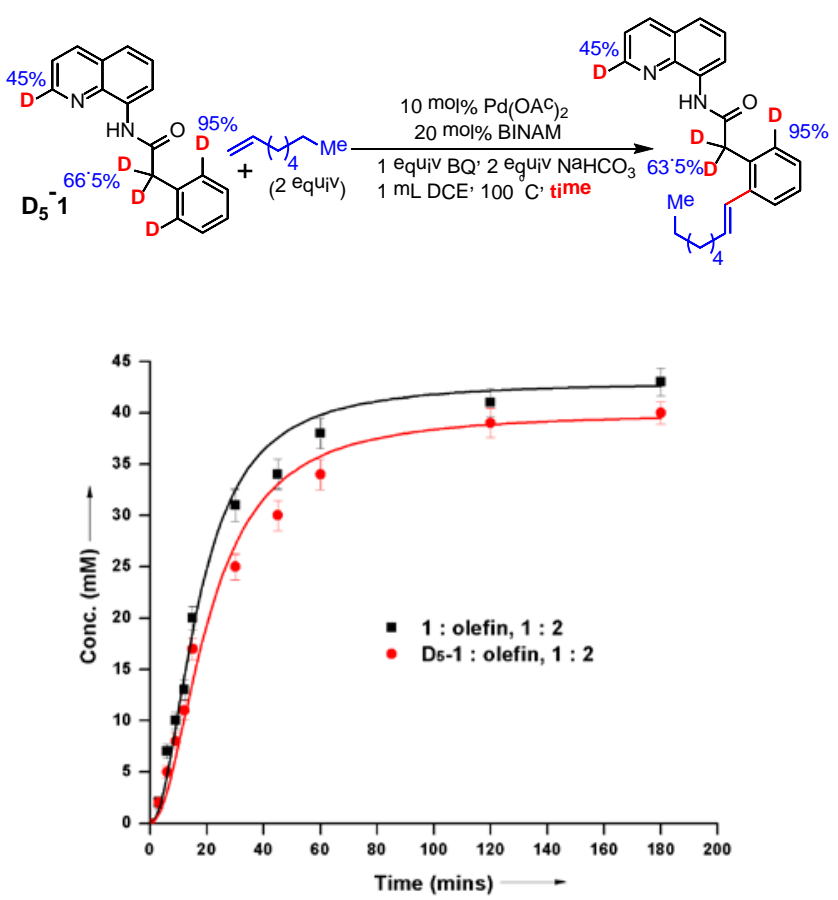

Figure 8. Plot of product concentration with respect to time for 1 and $D_{5^{-1}}$

rate constants involving $\mathbf{1}$ and $\mathbf{D}_{5}-\mathbf{1}\left(k_{H}\right.$ and $\left.k_{D}\right)$. A small KIE of 1.05 was obtained, consistent with the fact that $\mathrm{C}-\mathrm{H}$ activation of phenylacetamide is unlikely to be the ratedetermining step. ${ }^{25}$ Furthermore, when phenylacetamide was treated with $10 \mathrm{~mol} \% \mathrm{Pd}(\mathrm{OAc})_{2}$ in $\mathrm{D}_{4}-\mathrm{AcOH}, 95 \%$ deuterium incorporation was observed at the ortho positions $\left(\mathbf{D}_{5}-\mathbf{1}\right.$, Scheme 8). Our computations predict $\mathrm{C}-\mathrm{H}$ activation to be readily reversible, consistent with our experimental deuteration studies (see scheme 8 and Figure 2), and that it is faster than the subsequent steps involving the alkene.

Scheme 8. Addition of $\mathrm{D}_{4}-\mathrm{AcOH}$ to 1 suggested a reversible $\mathrm{C}-\mathrm{H}$ activation step
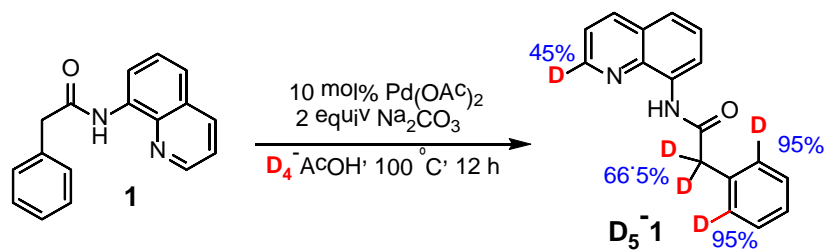

95\% deuterium incorporation at ortho position

After obtaining a small KIE value for the facile and reversible $\mathrm{C}-\mathrm{H}$ activation step, we examined the rate dependency of palladium. Keeping all other reagents constant, only palladium acetate was varied from $2.5 \mathrm{~mol} \%$ to $10 \mathrm{~mol} \%$ with respect to standard phenyl acetamide. Plotting the slopes from each of the graphs, first order rate dependency was obtained for palladium acetate (Figure 9).

$$
\begin{aligned}
\log \mathrm{k}_{o b s} & =1.00 \log [\mathrm{Pd}]-\mathbf{2 . 1 4 6} \\
\mathrm{d}[\text { product }] / \mathrm{dt} & =\mathrm{k}^{\prime}\left[\text { palladium acetate }{ }^{1}\right.
\end{aligned}
$$
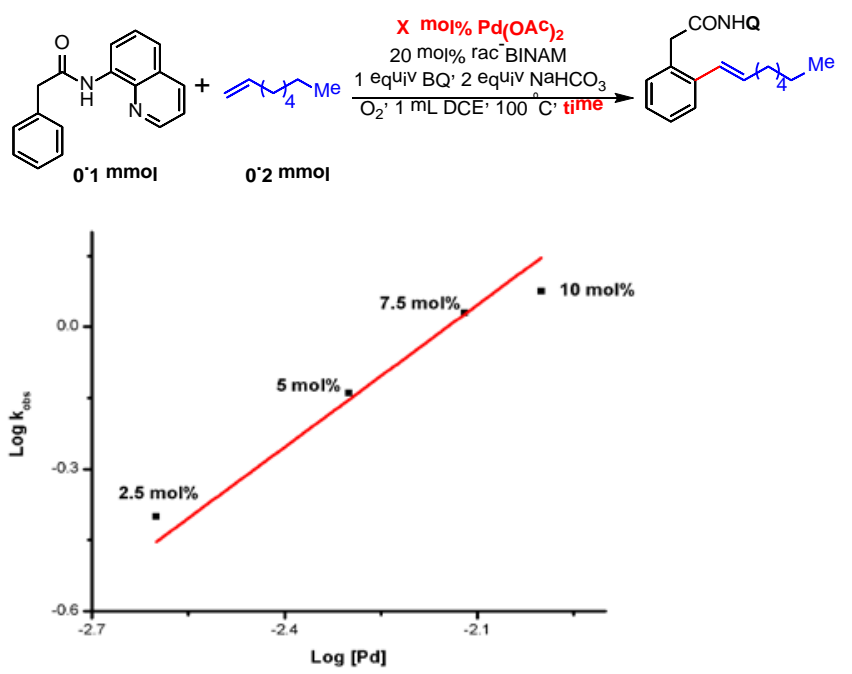

Figure 9. Order with respect to palladium acetate

Kinetic studies with $\beta, \beta$ - $\mathrm{D}_{2}$-biphenyl styrene (6) were then carried out (Figure 10). A primary KIE measurement of 2.84 was obtained based on a side-by-side comparison with undeuterated biphenyl styrene. This value implicates either $\beta$-hydride elimination or reductive eliminationas the overall turnover-limiting step in the catalytic cycle. Complete incorporation $(>99 \%)$ of deuterium was observed in the alkenylated product 7 (Scheme 9). Notably, no deuterium incorporation at the olefinated product $\mathrm{N}-\mathrm{H}$ bond was observed. This could suggest that reductive elimination from Pd-D involving the amide nitrogen atom does not occur. Alternatively any deuterium incorporation at this position is quickly washed out, which would be consistent with the low computed barrier $(5.3 \mathrm{kcal} / \mathrm{mol})$ for $\mathrm{N}-\mathrm{H}$ activation shown in Figure 2.

Scheme 9. Olefination of phenyl acetamide with $\beta, \beta-\mathrm{D}_{2^{-}}$ olefin 6
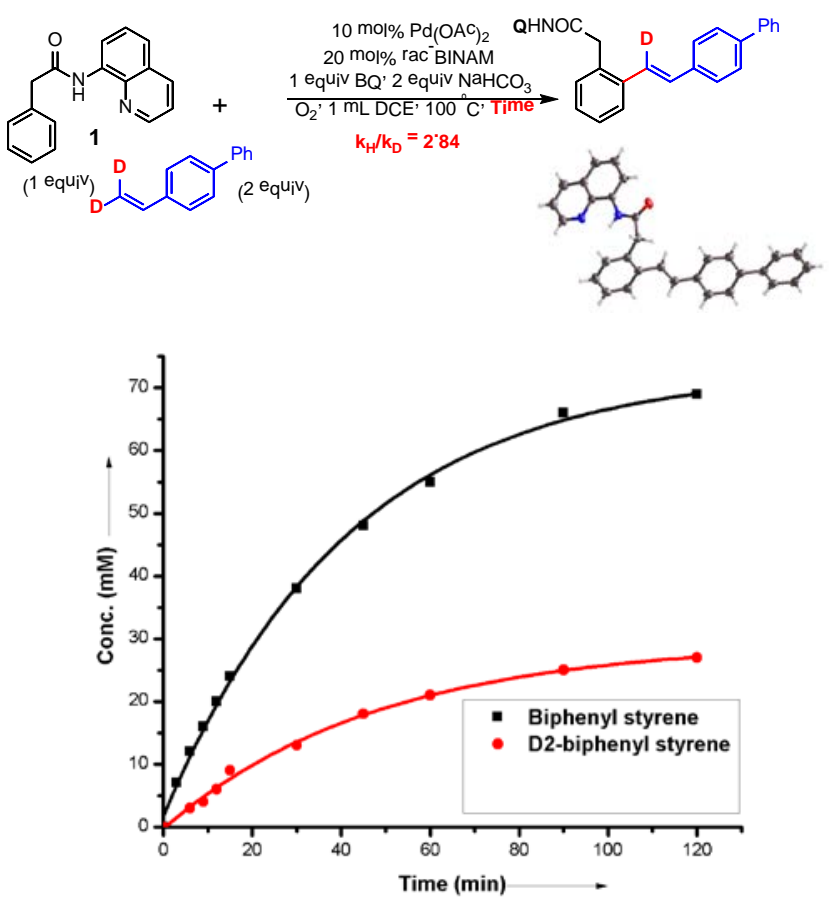
Figure 10. Comparison of product concentration with respect to time for styrene and $\beta, \beta-\mathrm{D}_{2}$-olefin 6

Electronic effects on the olefination with unactivated olefins: The reaction of 1-octene with a series of arylacetamides revealed the effect of electronic substition on the olefination reaction. Aryl acetamides substituted at the para- (3-Me, 3-OMe, 3-F and 3- $\mathrm{CF}_{3}$ ) and meta- (4-OMe, 4OEt, $4-\mathrm{NO}_{2}$ and $4-\mathrm{F}$ ) positions with respect to the olefination site were studied under the standard protocol. It was observed that the yield of olefinated product was highly dependent on the electronic effect of the substituents. ${ }^{14}$

Table 1. Effect of phenylacetamideelectronic substitution on $\mathrm{C}-\mathrm{H}$ olefination

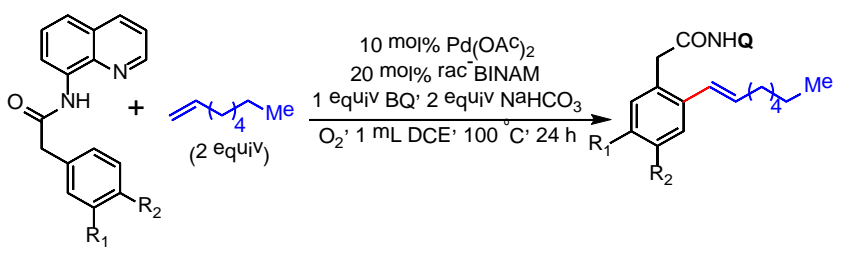

\begin{tabular}{lcc}
\hline Substituents $\left(\mathbf{R}_{\mathbf{1}}, \mathbf{R}_{\mathbf{2}}\right)$ & Yield (\%) & $\boldsymbol{k}_{\text {obs }}\left(\mathbf{M}^{-1} \mathbf{s}^{-1}\right)$ \\
\hline $\mathrm{R}_{1}=\mathrm{H}, \mathrm{R}_{2}=\mathrm{H}$ & 88 & 997.5 \\
$\mathrm{R}_{1}=\mathrm{CF}_{3}, \mathrm{R}_{2}=\mathrm{H}$ & 65 & $\mathbf{2 2 8 . 1}$ \\
$\mathrm{R}_{1}=\mathrm{H}, \mathrm{R}_{2}=\mathrm{F}$ & 55 & 386.6 \\
$\mathrm{R}_{1}=\mathrm{H}, \mathrm{R}_{2}=\mathrm{OMe}$ & 69 & 658.3 \\
$\mathrm{R}_{1}=\mathrm{OMe}, \mathrm{R}_{2}=\mathrm{H}$ & 73 & 538.2 \\
$\mathrm{R}_{1}=\mathrm{H}, \mathrm{R}_{2}=\mathrm{OEt}$ & 61 & 508.3 \\
$\mathrm{R}_{1}=\mathrm{Me}, \mathrm{R}_{2}=\mathrm{H}$ & 51 & 432.5 \\
\hline
\end{tabular}

The formation of the olefinated products from these substituted aryl acetamides was studied with respect to time. The rate constants were determined by initial slope calculation method. A Hammett analysis was carried out (Figure 11), giving a nonlinear, concave down ${ }^{26}$ plot indicative of a change in the rate-determining step. For inductively electron withdrawing groups a negative slope with a $\rho$-value of -0.83 is obtained, consistent with the accumulation of positive charge/depletion of negative charge in the aromatic ring of the turnover-determining TS (relative to the turnover-determining intermediate). A positive slope is obtained for electron donating substituents, indicative of opposite electronic effects in the turnover limiting step.

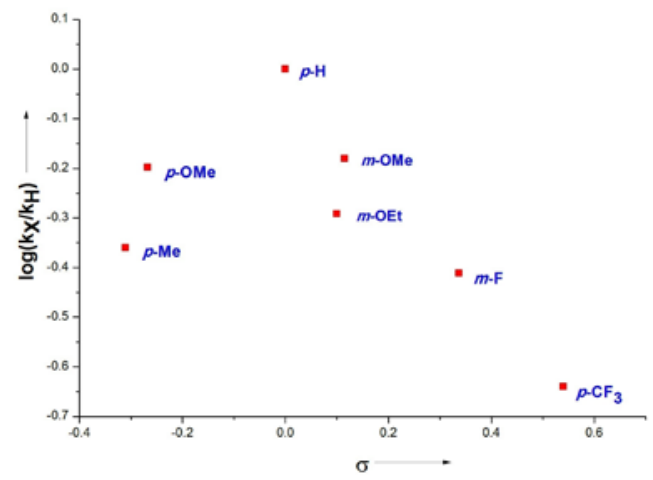

Figure 11.Hammett plot for $\mathrm{C}-\mathrm{H}$ olefination.

Computational analysis of the carbopalladation step with aliphatic alkenes. We computed the reaction of the palladacycle(Int-5) with propene as a model unactivated olefin with $n$-alkyl substituent (Figure 12). These calculations focus on the simpler BINAM-free reaction, which although less effective, turns over experimentally to give the linear olefination product. ${ }^{27}$

From Int-5, carbopalladation was computed to occur via TS-3 with a barrier of $22.0 \mathrm{kcal} / \mathrm{mol}$, forming the expanded 8-membered palladacycle. We located four distinct TS structures for this process: two each for linear and branched pathways in which the alkyl substituent is oriented either towards away from the aminoquinoline ligand.14 The computed Gibbs energy profile in Figure 12 corresponds to the formation of the observed major product: the linear $(E)$ alkene. In the ensuing intermediate Int- $\mathbf{6}$ the aromatic group coordinates the metal in $a n \eta^{2}$-fashion. This 8 -membered palladacycle must undergo a change in ring conformation to Int-7 to enable $\beta$-hydride elimination to occur, in which the aromatic coordination is replaced by a $\beta$-agostic $\left(r_{\mathrm{H} \ldots \mathrm{Pd}}=1.83\right.$ $\AA$ ) interaction. $\beta$-H elimination is predicted to be relatively facile, via TS-4 with a barrier of $5.5 \mathrm{kcal} / \mathrm{mol}$ from this intermediate. Formation of the minor (Z)-alkene stereoisomer by $\beta$-hydride elimination proceeds via a barrier $2.2 \mathrm{kcal} / \mathrm{mol}$ higher than the $(E)$-alkene. Assuming irreversible $\beta-\mathrm{H}$ elimination, the computed $E: Z$ stereoselectivity is therefore $20: 1$ at $100{ }^{\circ} \mathrm{C} .{ }^{28}$ However, we note that in order to access the palladacycle conformation leading to the $(Z)$-alkene the aromatic ring must flip from below to above the plane (or vice-versa) of the Pd(II)-center. Although it was not possible to locate a TS corresponding to this process, several torsional barriers must be overcome while the metal becomes coordinatively unsaturated. We reason that the barrier for this process is almost certainly greater than that of TS-4, excluding formation of the $(Z)$-alkene.

We were able to locate two pathways for the reductive elimination of $\mathrm{Pd}(\mathrm{II})$ hydride which remains coordinated by two $\mathrm{N}$ atoms and alkene: a relatively high energy intramolecular pathway via 3 -center $\mathbf{T S}-5,{ }^{29}$ or with the involvement of an external molecule of acid as proton shuttle a more feasible pathway via TS-6 is possible. $3^{\circ}$ In the intramolecular pathway, an $\mathrm{H}$ atom is transferred directly from the alkene to the product amide $\mathrm{N}-\mathrm{H}$ bond, while in the intermolecular pathway an external acid is responsible for amide protonation. The lack of any deuterium incorporation detected in the $\mathrm{N}-\mathrm{H}$ of the amide product using a deuterated alkene suggests that this latter pathway is more likely. 


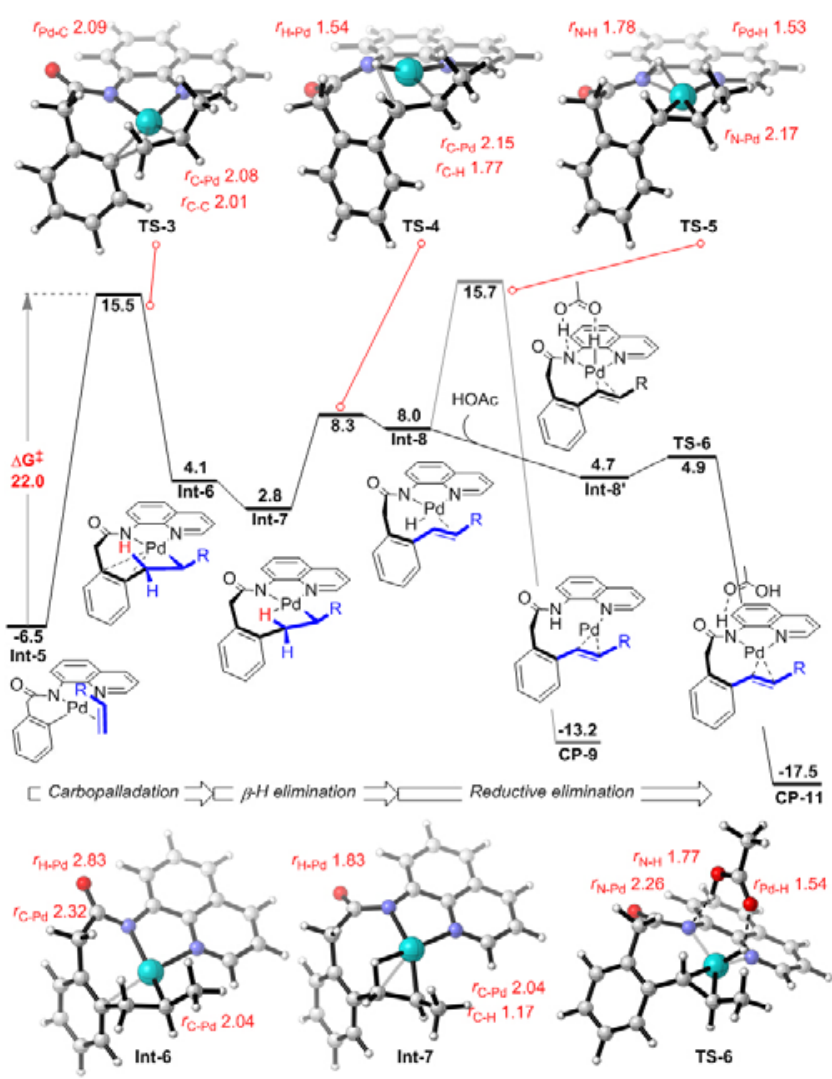

Figure 12. $\omega \mathrm{B} 97 \mathrm{XD} / \mathrm{def} 2-\mathrm{QZVPPGibbs}$ energy profile for successive carbopalladation, $\beta-\mathrm{H}$ elimination and reductive elimination steps, relative to the separated reagents and catalyst $(\mathrm{R}=\mathrm{Me})$.

Proceeding via the more favorable acid-assisted reductive elimination pathway, the mechanism in Figure 12 is kinetically feasible although it suggests carbopalladation is turnover-limiting and irreversible. However, such a mechanism is inconsistent with the primary KIE (2.84) obtained for deuterated alkenes (scheme 9), and furthermore, the relative TS stabilities for this step were also found to predict a lack of selectivity for the linear alkene product. Relative Gibbs energies of the most stable TSs leading to linear and branched insertion products are similar, giving a predicted linear:branched ratio of 1.2:1 as a consequence. This underestimates the experimental regioselectivity of 4:1 (without BINAM) in favor of the linear isomer, which corresponds to a free energy difference of 1.0 $\mathrm{kcal} / \mathrm{mol}$ at $100{ }^{\circ} \mathrm{C} .{ }^{14}$ Based on these inconsistencies, we considered an alternative model involving the intervention of cationic intermediates to rationalize the experimental observations.

Comparison of neutral and cationic pathways. Since the neutral pathway failed to account for kinetic and selectivity data, we considered the reactivity of positively charged intermediates..$^{31}$ Computationally, it is difficult to compare the relative stabilities of intermediates with different overall charge due to large differences in solvation energies; $3^{2}$ thus we restrict our attention solely to reactivity, as judged by the barrier heights for $\mathrm{C}-\mathrm{H}$ activation and migratory insertion. Alongside neutral complexes Int-2 and Int-5 we considered cationic intermediates formed by amide $N$-protonation (which was more stable than $O$-protonation or pyridine protonation), or by coordination to $\mathrm{Na}^{+}$(which was more stable at $\mathrm{O}$ than $\mathrm{N}$ ).
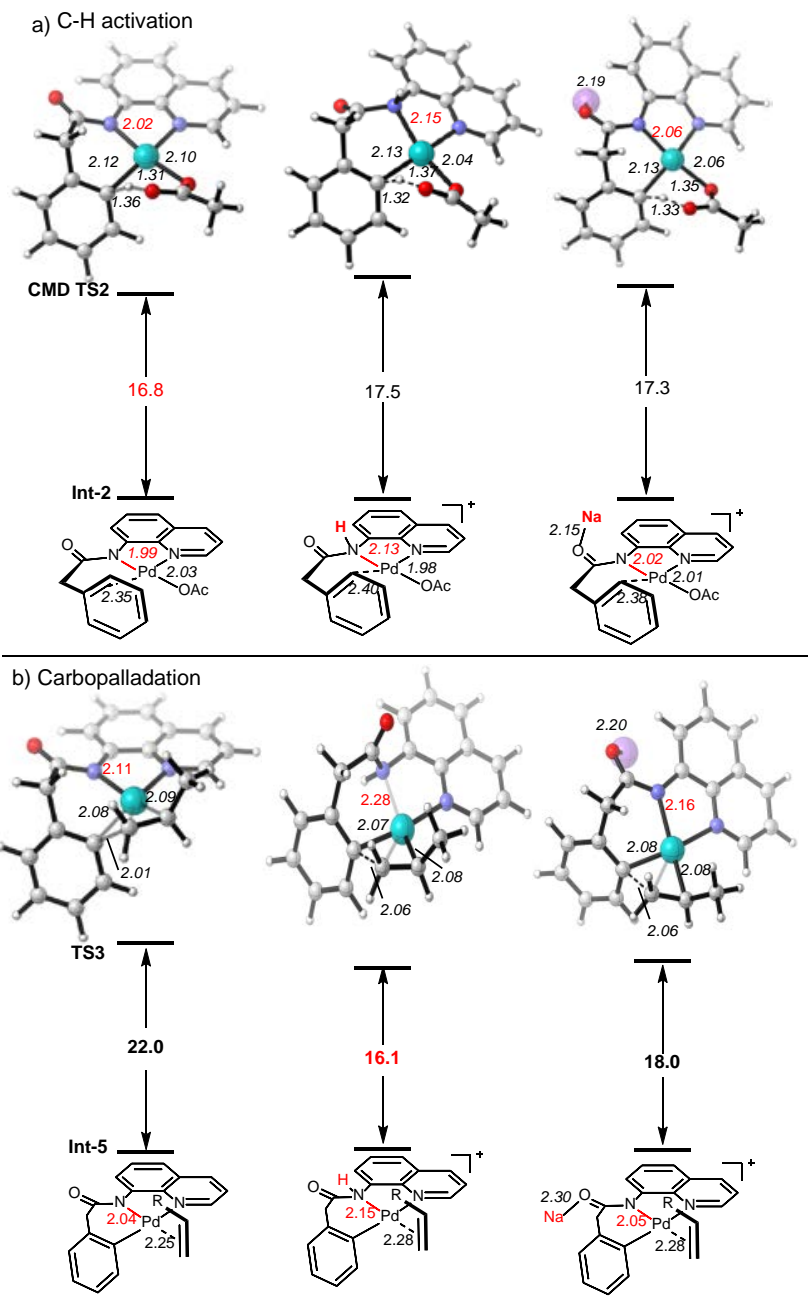

Figure 13. $\omega \mathrm{B} 97 \mathrm{XD} / \mathrm{def} 2-\mathrm{QZVPPC}-\mathrm{H}$ activation and carbopalladation barriers for neutral and cationic intermediates.

Although the barrier heights for $\mathrm{C}-\mathrm{H}$ activation are unchanged, we observed much greater reactivity towards migratory insertion for the cationic intermediates (Figure 13). For the protonated form, the barrier for carbopalladation is $5.9 \mathrm{kcal} / \mathrm{mol}$ lower than for the neutral form. As discussed previously, the computed relative stabilities of neutral and protonated forms of Int-5 should be interpreted with caution: nevertheless, $N$-protonation of Int-5 by the conjugate acid of BINAM was found to be exergonic by 6.9 $\mathrm{kcal} / \mathrm{mol}$ (see SI).33

The reaction of cationic intermediate Int-9 with propene is shown in Figure 14. Carbopalladation is faster and also thermodynamically more favorable than for the neutral pathway in Figure 12. The $\beta$-hydride elimination step (via TS8) is now turnover-limiting with the largest barrier of 19.6 $\mathrm{kcal} / \mathrm{mol}$ from the stable intermediate Int-1o. Although $\beta$ hydride elimination is slower, the linear/branched selectivity results from the carbopalladation step, since this occurs irreversibly. The computed level of regioselectivity from linear TS-7 and its branched regioisomer is 7:1, which compares favorably with experimental values of $4: 1$ to $8: 1 .^{14}$ For both substrates, the branched carbopalladation TS is less 
stable than either linear TS-7 or TS-8. Linear regioselectivity thus results in both cases, which for styrene involves turnover-and selectivity determining $\beta$-hydride elimination. For propene carbopalladation is selectivity determining, while $\beta$-hydride elimination limits turnover. Stereoselectivity is controlled in $\beta$-hydride elimination step: for both substrates, there is a clear preference for $(E)$-alkene formation.

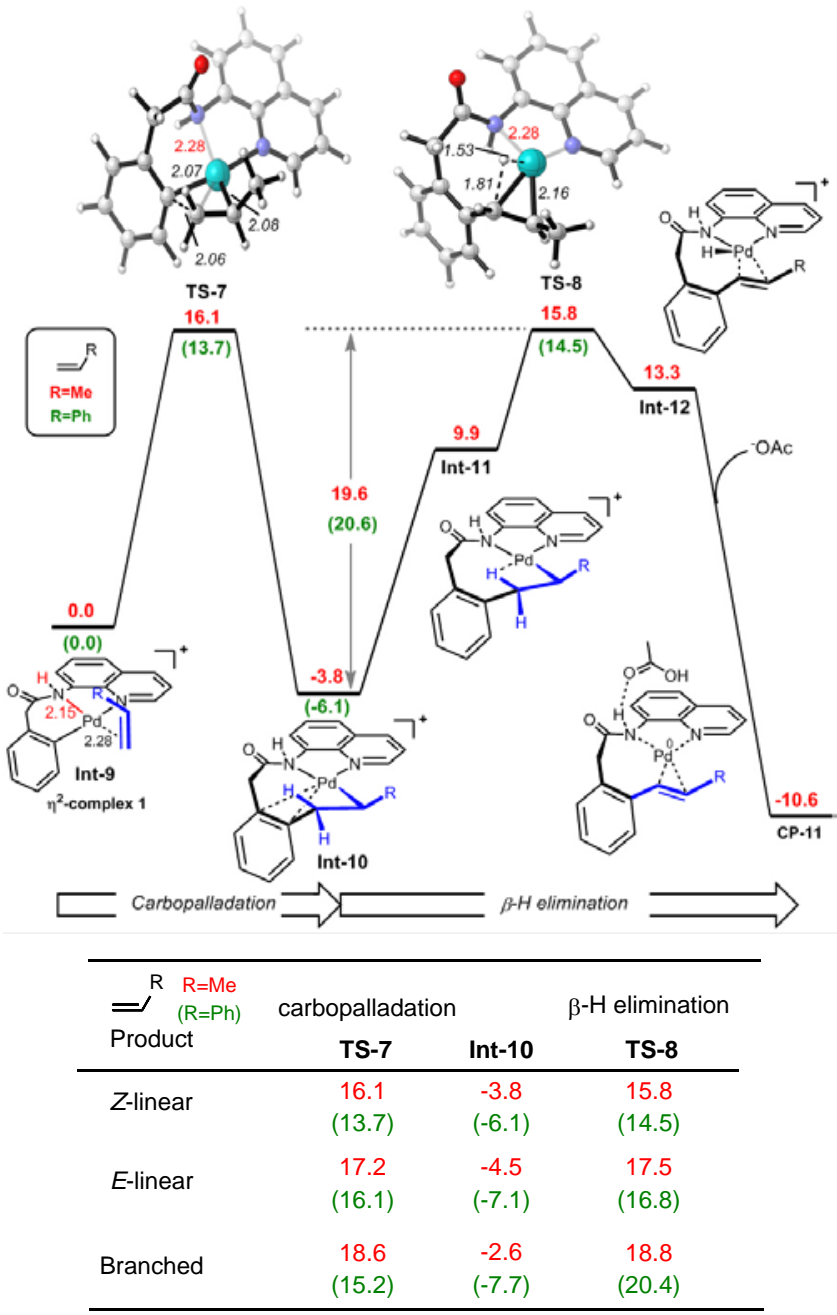

Figure 14. $\omega \mathrm{B} 97 \mathrm{XD} / \mathrm{def}$-QZVPP Gibbs energy profile for a cationic process. The reaction with propene $(\mathrm{R}=\mathrm{Me})$ and styrene $(\mathrm{R}=\mathrm{Ph})$ are shown in red and green, respectively.

The experimentally determined KIE value of 2.84 was obtained for 4-vinylbiphenyl: to compare our computational results we used styrene as model substrate, although the computed PES is very similar to that obtained for propene (Figure 14). We initially applied the Bigeleisen-Mayer equation34 (without tunneling corrections) to TS-8, obtaining a predicted KIE value of 3.32 for this step alone. A value of 2.66 has been obtained previously for syn-elimination. 35 However, isotope effects may result from the compound effect of rate differences for several elementary steps in a catalytic cycle: in the present case TS-7 and TS-8 are relatively close in Gibbs energy. ${ }^{36}$ Assuming the carbopalladation intermediate to be in steady state, we derived an expression for the rate of the product formation with first order dependence on both substrate and catalyst (see SI): carbopalladation combines with the primary KIE of syn- $\beta$-hydride elimination to give a predicted value of $\mathbf{2 . 7 2}$ (2.79 with a $1 \mathrm{D}$-tunneling correction) that compares favorably with experimental value.

Substrate scope: activated vs. unactivated alkenes. The present methodology is applicable for unactivated alkenes which are typically unreactive. From our mechanistic study, $\mathrm{C}-\mathrm{H}$ activation was found to be facile and reversible, while the carbopalladation process determines regioselectivity. We have computed the reactivity of various alkenes towards migratory insertion, applying an activation strain/distortioninteraction energy decomposition analysis to the TS structures in Figure 15. Here the activation barrier is decomposed into an unfavorable strain energy term for the two reactants relative to their undistorted ground-state structures, and a favorable intermolecular interaction energy. ${ }^{37-39}$ Our findings clearly show that reactivity is controlled by the alkene distortion energies: the other terms are remarkably insensitive to a change in alkene or charge on the palladacycle.

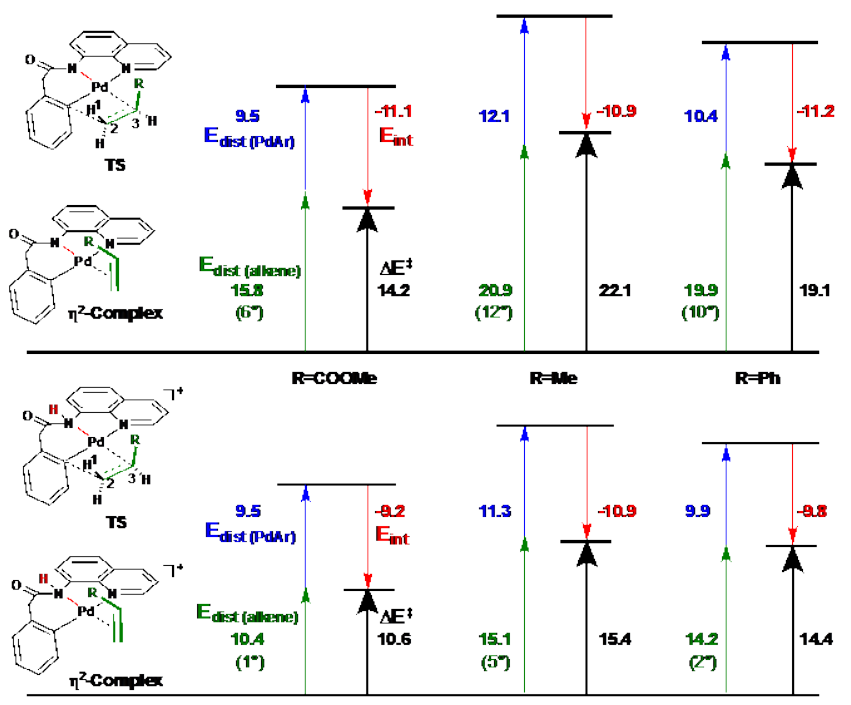

Figure 15. $\omega \mathrm{B} 97 \mathrm{XD} / \mathrm{def2}-\mathrm{QZVPP}$ activation, distortion, and interaction energies: green: alkene distortion energy, blue: palladacycledistortion energy, red: interaction energy, and black: activation energy $(\mathrm{kcal} / \mathrm{mol}) . \mathrm{H}_{1}-\mathrm{C}_{2}-\mathrm{C}_{3}-\mathrm{R}$ torsional strain $\left(^{\circ}\right)$ in the TS in parentheses.

Experimentally, with 1-octene the yield of olefinated product reaches $45-50 \%$ after $2 \mathrm{~h}$, but for the activated olefin t-butyl acrylate this rises to $60-70 \%$ after $2 \mathrm{~h}$. Computed activation barriers reproduce this trend in reactivity, and also confirm the higher reactivity of a cationic intermediate. Decomposition of these activation barriers reveals that the distortion energy of the palladacycle and the interaction energy are consistent in magnitude in all systems, being equal and opposite in magnitude. As a result, the alkene distortion energy closely mirrors the activation barrier. This distortion reflects the degree of torsional strain in each TS structure, and is strongly correlated $\left(R^{2}=0.94\right)$ with the H1$\mathrm{C}_{2}-\mathrm{C}_{3}-\mathrm{R}$ dihedral angle. $4^{\circ}$ Electronic effects are important: carbopalladation is accelerated either by EDG and EWG alkene susbtituents, ${ }^{41}$ or by weakening ligation to $\mathrm{Pd}$ to enable reactivity with unactivated alkenes. This manifests itself through earlier TS structures with correspondingly smaller alkene distortion energies. 
Based on experimental and computational studies, we propose that the overall mechanism combines neutral and cationic pathways as follows (Scheme 10): the rapid and reversible $\mathrm{C}$-Hactivationof (B) forms neutral arylpalladium intermediate (C). Co-ordination of an unactivated olefin to this neutral arylpalladium species is possible, however, reactivity requires a positively charged intermediate (D), for which we hypothesize that rac-BINAM may act as protonshuttle. Intermediate (D) undergoes 1,2-migratory insertion with the olefin to generate intermediate E. From this intermediate turnover-limiting $\beta$-hydride elimination step forms the kinetically- and thermodynamically-favored linear olefination product.

Scheme 10.Proposed mechanism for $\mathrm{C}-\mathrm{H}$ olefination

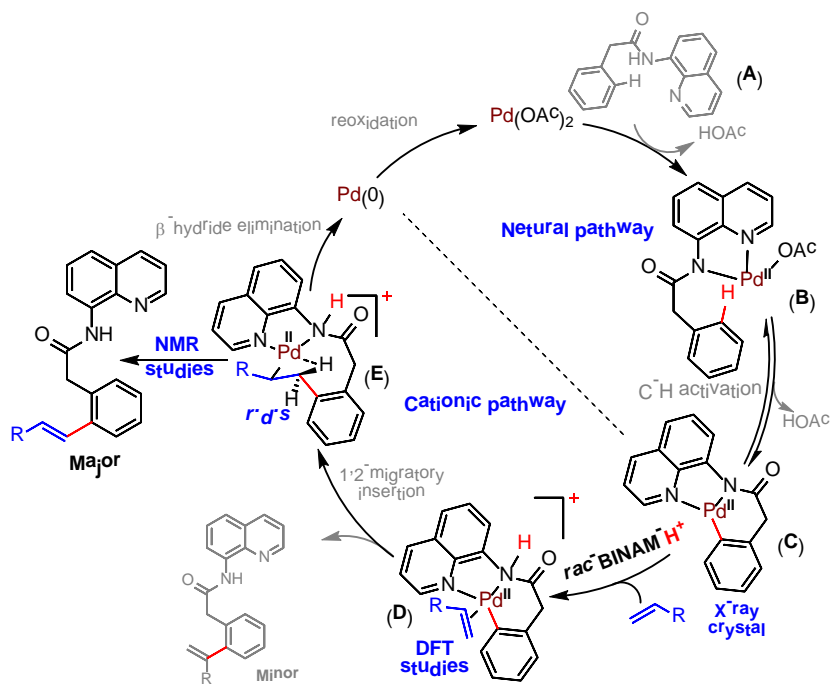

\section{CONCLUSION}

In summary, $\mathrm{Pd}$-catalyzed regioselective $\mathrm{C}-\mathrm{H}$ olefination with unactivated, aliphatic olefins has been studied by detailed mechanistic experiments to shed light on the elementary steps involved in this multistep catalytic process. A series of intermediate arylpalladium complexes have been characterized by X-ray crystallography. Arene $\mathrm{C}-\mathrm{H}$ activation, olefin coordination and carbopalladation steps have been rationalized through NMR and kinetic measurements with the help of these catalytically-competent aryl palladium species. The roles of different optimized reaction components for this $\mathrm{C}-\mathrm{H}$ olefination were studied by initial kinetics interpretation. The rate dependency along with kinetic isotope effect (KIE) revealed that instead of $\mathrm{C}-\mathrm{H}$ activation, $\beta$-hydride elimination step is turnover-limiting for the overall catalytic process. These experimental results are supported by DFT studies and have proven to be effective to understand the origins of regioselectivity and stereoselectivity. The success of this system to achieve stereoselective olefination with unactivated olefins is attributable to a cationic pathway for carbopalladation. The proton shuttling tendency of BINAM leads to differences from other olefination methods by creating a positively charged organopalladium intermediate. Computed alkene distortion energies, which control the insertion barrier, are reduced for this cationic intermediate. These findings will be useful for the continued development of controlled olefination methodologies for a variety of unactivated alkenes.

\section{ACKNOWLEDGEMENT}

This research was supported by SERB(EMR/2015/ooo164) and Royal Society (RG110617). Fellowships from CSIR-India (AD) and European Community (FP7-PEOPLE-2012-IIF under grant agreement 330364 and 912364 to QP) are gratefully acknowledged. We acknowledge the CSA-trust grant to QP and the use of the EPSRC UK National Service for Computational Chemistry Software (CHEM870).

\section{AUTHOR INFORMATION}

Corresponding Authors: qpeng@nankai.edu.cn; robert.paton@chem.ox.ac.uk (computational studies); dmaiti@iitb.ac.in (experimental studies)

Supporting Information Available: Experimental procedures and characterization data for all compounds.Computational methods, calculated regioselectivities, unfavorable pathways, absolute free energies and Cartesian coordinates of all computed stationary points.This material is available free of charge via the Internet at http://pubs.acs.org

\section{REFERENCES}

1. For $\mathrm{C}-\mathrm{C}$ bond forming name reactions using [R-Pd(II)], see:(a) Negishi, E.; King, A. O.; Okukado, N. J. Org. Chem. 1977, 42, 1821. (b) Miyaura, N.; Yamada, K.; Suzuki, A. Tetrahedron Lett. 1979, 20, 3437. (c) Miyaura, N.; Suzuki, A. J. Chem. Soc., Chem. Commun. 1979, 866. (d) Negishi, E. Acc. Chem. Res. 1982, 15, 340. (e) Hatanaka, Y.; Hiyama, T. J. Org. Chem. 1988, 53, 918. (f) Miyaura, N.; Suzuki, A. Chem. Rev. 1995, 95, 2457. (g) Denmark, S. E.; Regens, C. S. Acc. Chem. Res. 2oo8, 41, 1486.

2. For $\mathrm{C}$-heteroatom bond forming name reactions using [R-Pd(II)], see: (a) Trost, B. M. Acc. Chem. Res. 1980, 13, 385. (b) Paul, F.; Patt, J.; Hartwig, J. F. J. Am. Chem. Soc. 1994,116, 5969. (c) Guram, A. S.; Buchwald, S. L. J. Am. Chem. Soc. 1994, 116, 7901. (d) Ishiyama, T.; Murata, M.; Miyaura, N. J. Org. Chem. 1995, 6o, 7508. (e) Watson, D. A.; Su, M.; Teverovskiy, G.; Zhang, Y.; Garcia-Fortanet, J.; Kinzel, T.; Buchwald, S. L. Science 2009, 325, 1661.

3. For initial reports of the Mizoroki-Heck coupling, see: (a)Mizoroki, T.; Mori, K.; Ozaki, A. Bull. Chem. Soc. Jpn. 1971, 44, 581. (b) Heck, R. F.; Nolley, J. P., Jr. J. Org. Chem. 1972, 37, 2320. (c) Heck, R. F. Acc. Chem. Res. 1979, 12, 146. (d) Plevyak, J. E.; Dickerson, J. E.; Heck, R. F. J. Org. Chem. 1979, 44, 4078. (e) Beletskaya, I. P.; Cheprakov, A. V. Chem. Rev. 2000, 100, 3009. (f) Dounay, A. B.; Overman, L. E. Chem. Rev. 2003, 103, 2945. (g) Nicolaou, K. C.; Bulger, P. G.; Sarlah, D. Angew. Chem., Int. Ed. 2005, 44, 4442. (h) Oestreich, M. The Mizoroki-Heck Reaction, Wiley, Chichester, 2009 (i) Le Bras, J.; Muzart, J. Chem. Rev. 2011, 111, 1170. (i) Cartney, D. M.; Guiry, P. J. Chem. Soc. Rev. 2o11, 40, 5122.

4. For reviews on $\mathrm{Pd}$-catalyzed $\mathrm{C}-\mathrm{H}$ functionalization reactions, see (a) Alberico, D.; Scott, M. E.; Lautens, M. Chem. Rev. 2007, 107, 174. (b) Hartwig, J. F. Nature 2008, 455, 314. (c) Ackermann, L.; Vicente, R.; Kapdi, A. R. Angew. Chem., Int. Ed. 2009, 48, 9792. (d) Daugulis, O.; Do, H.-Q.; Shabashov, D. Acc. Chem. Res. 2009, 42, 1074. (e) Colby, D. A.; Bergman, R. G.; Ellman, J. A. Chem. Rev. 2009, 110, 624. (f) Chen, X.; Engle, K. M.; Wang, D.-H.; Yu, J.-Q. Angew. Chem., Int. Ed. 2009, 48, 5094. (g) Lyons, T. W.; Sanford, M. S. Chem. Rev. 2010, 110, 1147. (h) Sun, C.-L.; Li, B.-J.; Shi, Z.-J. Chem. Rev. 2010, 111, 1293. (i) McMurray, L.; O'Hara, F.; Gaunt, M. J. Chem. Soc. Rev. 2o11, 40, 1885. (j) Song, G.; Wang, F.; Li, X. Chem. Soc. Rev. 2012, 41, 3651. (k) Arockiam, P. B.; Bruneau, C.; Dixneuf, P. H. Chem. Rev. 2012, 112, 5879.

5. For initial reports of the Fujiwara-Moritani reaction, see: (a) Moritani, I.; Fujiwara, Y. Tetrahedron Lett. 1967, 1119. (b)Fujiwara, 
Y.; Moritani, I.; Matsuda, M.; Teranishi, S. Tetrahedron Lett. 1968 9, 633. (c) Fujiwara, Y.; Moritani, I.; Danno, S.; Asano, R.; Teranishi, S. J. Am. Chem. Soc. 1969, 91, 7166. (d) Asano, R.; Moritani, I.; Fujiwara, Y.; Teranishi, S. J. Chem. Soc. Chem.Commun. 1970, 1293.(e) Jia, C. G.; Kitamura, T.; Fujiwara, Y. Acc. Chem. Res. 2001, 34, 844. (f) Zhou, L.; Lu, W. Chem. Eur. J. 2014, 20, 634 .

6. For selected examples of ruthenium catalyzed $\mathrm{C}-\mathrm{H}$ olefination, see: (a) Weissman, H.; Song, X. P.; Milstein, D. J. Am. Chem. Soc. 2001, 123, (b) Kwon, K.-H.; Lee, D. W.; Yi, C. S. Organomet. 2010, 29, 5748. (c) Ackermann, L.; Pospech, J. Org. Lett. 2011, 13, 4153. (d) Padala, K.; Jeganmohan, M. Org. Lett. 2011, 13, 6144. (e) Arockiam, P. B.; Fischmeister, C.; Bruneau, C.; Dixneuf, P. H. Green Chem. 2011, 13, 3075. (f) Ackermann, L.; Wang, L.; Wolfram, R.; Lygin, A V. Org. Lett. 2012, 14, 728. (g) Li, B.; Ma, J.; Wang, N.; Feng, H.; Xu, S.; Wang, B. Org. Lett. 2012, 14, 736. (h) Padala, K.; Jeganmohan, M. Org. Lett. 2012, 14, 1134. (i) Kozhushkov, S. I.; Ackermann, L. Chem. Sci. 2013, 4, 886. (j) Li, B.; Ma, J.; Xie, W.; Song, H.; Xu, S.; Wang, B. J. Org. Chem. 2013, 78, 9345.

7. For selected examples of rhodium catalyzed $\mathrm{C}-\mathrm{H}$ olefination, see: (a) Umeda, N.; Hirano, K.; Satoh, T.; Miura, M. J. Org. Chem. 20o9, 74, 7094. (b) Wang, F.; Song, G.; Li, X. Org. Lett. 2010, 12, 5430. (c) Satoh, T.; Miura, M. Chem. Eur. J. 2010, 16, 11212. (d) Gong, T.-J.; Xiao, B.; Liu, Z.-J.; Wan, J.; Xu, J.; Luo, D.-F.; Fu, Y.; Liu, L. Org. Lett. 2011, 13, 3235. (e) Rakshit, S.; Grohmann, C.; Besset, T.; Glorius, F. J. Am. Chem. Soc. 2011, 133, 2350. (f) Li, H.; Li, Y.; Zhang, X.-S.; Chen, K.; Wang, X.; Shi, Z.-J. J. Am. Chem. Soc. 2011, 133, 15244. (g) Patureau, F. W.; Besset, T.; Glorius, F. Angew. Chem., Int. Ed. 2011, 50, 1064. (h) Park, S. H.; Kim, J. Y.; Chang, S. Org. Lett. 2o11, 13, 2372. (i) Wang, C.; Chen, H.; Wang, Z.; Chen, J.; Huang, Y. Angew. Chem., Int. Ed. 2012, 51, 7242. (j) Patureau, F. W.; WencelDelord, J.; Glorius, F. Aldrichimica Acta 2012, 45, 31. (k) Liu, B.; Fan, Y.; Gao, Y.; Sun, C.; Xu, C.; Zhu, J. J. Am. Chem. Soc. 2013, 135, 468. (l) Zhou, J.; Li, B.; Hu, F.; Shi, B.-F. Org. Lett. 2013, 15, 3460. (m) Shen, Y.; Liu, G.; Zhou, Z.; Lu, X. Org. Lett. 2013, 15, 3366. (n) Feng, C.; Feng, D.; Loh, T.-P. Org. Lett. 2013, 15, 3670. (o) Zhou, J.; Li, B.; Qian, Z-C.; Shi, B.-F. Adv. Synth. Catal. 2014, 356, 1038.

8. (a) Miura, M.; Tsuda, T.; Satoh, T.; Pivsa-Art, S.; Nomura, M. J. Org. Chem. 1998, 63, 5211. (b) Grimster, N. P.; Gauntlett, C.; Godfrey, C. R. A.; Gaunt, M. J. Angew. Chem., Int. Ed. 2005, 44 3125. (c) Cai, G.; Fu, Y.; Li, Y.; Wan, X.; Shi, Z. J. Am. Chem. Soc. 2007, 129, 7666. (d) Cho, S. H.; Hwang, S. J.; Chang, S. J. Am. Chem. Soc. 20o8, 130, 9254. (e) Zhang, Y.-H.; Shi, B.-F.; Yu, J.-Q. J. Am. Chem. Soc. 2009, 131, 5072. (f) García-Rubia, A.; Arrayás, R. G.; Carretero, J. C. Angew. Chem., Int. Ed. 2009, 48, 6511. (g) Engle, K. M.; Wang, D.-H.; Yu, J.-Q. Angew. Chem., Int. Ed. 2010, 49, 6169. (h) Wang, D.-H.; Engle, K. M.; Shi, B.-F.; Yu, J.-Q. Science 2010, 327, 315. (i) Wasa, M.; Engle, K. M.; Yu, J.-Q. J. Am. Chem. Soc. 2010, 132, 368o. (j) Shi, B.-F.; Zhang, Y.-H.; Lam, J. K.; Wang, D.-H.; Yu, J.-Q. J. Am. Chem. Soc. 2010, 132, 46o. (k) Engle, K. M.; Wang, D.-H.; Yu, J.-Q. J. Am. Chem. Soc. 2010, 132, 14137. (l) Wang, L.; Liu, S.; Li, Z.; Yu, Y. Org. Lett. 2o11, 13, 6137. (m) Garcia-Rubia, A.; Urones, B.; Gomez Arrayas, R.; Carretero, J. C. Angew. Chem., Int. Ed. 2011, 50, 10927. (n) Huang, C.; Chattopadhyay, B.; Gevorgyan, V. J. Am. Chem. Soc. 2011, 133, 12406. (o) Wang, C.; Ge, H. Chem. Eur. J. 2011, 17, 14371. (p) Li, D.-D.; Yuan, T.-T.; Wang, G.-W. Chem. Commun. 2011, 47, 12789. (q)Liang, Z.; Ju, L.; Xie, Y.; Huang, L.; Zhang, Y. Chem. Eur. J. 2012, 18, 15816. (r) Wang, L.; Guo, W.; Zhang, X.-X.; Xia, X.-D.; Xiao, W.-J. Org. Lett. 2012, 14, 740. (s) Yu, M.; Xie, Y.; Xie, C.; Zhang, Y. Org. Lett. 2012, 14, 2164. (t) Liu, W.; Li, Y.; Xu, B.; Kuang, C. Org. Lett. 2013, 15, 2342. (u) Engle, K. M.; Yu, J.-Q. J. Org. Chem. 2013, 78, 8927. (v) Liu, Q.; Li, Q.; Ma, Y.; Jia, Y. Org. Lett. 2013, 15, 4528. (w) Nandi, D.; Ghosh, D.; Chen, S.-J.; Kuo, B.-C.; Wang, N. M.; Lee, H. M. J. Org. Chem. 2o13, 78, 3445. (x) Wang, H.-L.; Hu, R.-B.; Zhang, H.; Zhou, A.-X.; Yang, S.-D. Org. Lett. 2013, 15, 5302. (y) Liu, B.; Jiang, H.-Z.; Shi, B.-F. J. Org. Chem. 2014, 79, 1521. (z) Hu, J.; Guan, M.; Han, J.;Huang,Z.-B.;Shi,D.Q.Zhao,Y. J. Org. Chem. 2014, 8o, 7896.

9. For a recent review on $\sigma$-chelating directing groups, see: (a) Yu, J.Q.; Giri, R.; Chen, X. Org. Biomol. Chem. 20o6, 4, 4041. (b) Chen,
Z.; Wang, B.; Zhang, J.; Yu, W.; Liu, Z.; Zhang, Y. Org. Chem. Front. 2015, 2, 1107 .

10. For palladium catalyzed meta-selective arene $\mathrm{C}-\mathrm{H}$ functionalization, see: (a) Leow, D.; Li, G.; Mei, T.-S.; Yu, J.-Q. Nature 2012, 486, 518. (b) Dai, H.-X.; Li, G.; Zhang, X.-G.; Stepan, A. F.; Yu, J.-Q. J. Am. Chem. Soc. 2013, 135, 7567. (c) Wan, L.; Dastbaravardeh, N.; Li, G.; Yu, J.-Q. J. Am. Chem. Soc. 2013, 135, 18056. (d) Lee, S.; Lee, H.; Tan, K. L. J. Am. Chem. Soc 2013, 135, 18778. (e) Tang, R.-Y.; Li, G.; Yu, J.-Q. Nature 2014, 507, 215. (f) Bera, M.; Modak, A.; Patra, T.; Maji, A.; Maiti, D. Org. Lett. 2o14, 16, 576o. (g) Bera, M; Maji, A.; Sahoo, S. K.; Maiti, D.Angew. Chem., Int. Ed. 2015, 54, 8515. (h) Patra, T.; Watile, R. A.; Agasti, S.; Togati, N.; Maiti, D.Chem. Commun., 2015, 52, 2027.(i) Li, S.; Cai, L.; Ji, H.; Li, G. Nat. Commun. doi1o.1038/ncomms10443. (j) Bera, M.; Sahoo, S. K.; Maiti, D. ACS Catal., 2o16, 6, 3575.

11. For directing group assisted para-C-H activation, see: (a) Bag, S.; Patra, T.; Modak,A.; Deb, A.; Maity, S.; Dutta, U.; Dey, A.; Kancherla, R.; Maji, A.; Hazra, A.; Bera, M.; Maiti, D. J. Am. Chem. Soc.2015, 137, 11888. (b) Patra, T.; Bag, S.; Kancherla, R.; Mondal, A.; Dey, A.; Pimparkar, S.; Agasti, S.; Modak, A.; Maiti, D. Angew. Chem., Int. Ed. 2016, 55, 7751.

12. For olefination with unactivated olefins, see (a) Daves, G. D.; Hallberg, A. Chem. Rev. 1989, 89, 1433. (b) Delcamp, J. H.; White, M. C. J. Am. Chem. Soc. 2006, 128, 15076. (c) Fall, Y.; Berthiol, F.; Doucet, H.; Santelli, M. Synthesis 2007, 1683. (d) Delcamp, J. H.; Brucks, A. P.; White, M. C. J. Am. Chem. Soc. 2008, 130, 11270. (e) $\mathrm{Su}$, Y.; Jiao, N.Org. Lett. 2009, 11, 2980.(f) Tsai, A. S.; Brasse, M.; Bergman, R. G.; Ellman, J. A. Org. Lett. 2o11, 13, 540. (g) Werner,E. W.; Sigman, M. S.J. Am. Chem. Soc. 2o11, 133, 9692.(h) Qin, L.; Ren, X.; Lu, Y.; Li, Y.; Zhou, J. Angew. Chem., Int. Ed. 2012, 51, 5915. (i) Qin, L.; Hirao, H.; Zhou, J. Chem. Commun. 2013, 49, 10236.(j) Sevov, C. S.; Hartwig, J. F. J. Am. Chem. Soc. 2014, 136, 10625. (k) Xue, X.; Xu, J.; Zhang, L.; Xu, C.; Pan, Y.; Xu, L.; Li, H.; Zhang, W. Adv. Synth. Catal. 2016, 358, 573.

13.Deb, A.; Bag, S.; Kancherla, R.; Maiti, D. J. Am. Chem. Soc. 2014, $136,13602$.

14. See supporting information for further details.CCDC1446086, CCDC 1446050,CCDC 1446049 (Figure 1), CCDC 1518907 (Scheme 4) andCCDC 1501472 (Scheme 9) can be obtained from http://www.ccdc.cam.ac.uk/data_request/cif

15. For discussions on best practice in application of computational studies to organometallic catalysis see: (a) Santoro, S.; Kalek, M.; Huang, G.; Himo, F. Acc. Chem. Res. 2016, 49 , 1006; (b) Zhang, X.; Chung, L. W.; Wu, Y.-D. Acc. Chem. Res. 2016, 49 , 1302; (c) Peng, Q.; Paton, R. S. Acc. Chem. Res. 2016, 49, 1042; (d) Sperger, T.; Sanhueza, I. A.; Schoenebeck, F. Acc. Chem. Res. 2016, 49, 1311.

16. (a) All calculations were performed with Gaussian o9, Revision D.o1, Frisch, M. J. et al. Gaussian, Inc., Wallingford CT, 2009. See supporting information for full details of computational methods; (b) $\omega_{B} 97 X D$ : Chai, J.-D.; Head-Gordon, M. Phys. Chem. Chem. Phys. 2008, 10, 6615; (c) Mo6: Zhao, Y.;Truhlar, D.G. Theor Chem Account.2006, 120, 215. (d) def2-QZVPP: Weigend, F. Phys. Chem. Chem. Phys. 2oo6, 8, 1057; (e) CPCM: Cossi, M.; Rega, N. ;Scalmani, G.; Barone, V. J. Comp. Chem. 2003, 24, 669.

17. Sperger, T.; Sanhueza, I. A.; I. Kalvet, Schoenebeck, F. Chem. Rev. 2015, 115, 9532.

18. Funes-Ardoiz, I.; Paton, R. S. GoodVibes v1.o.1 DOI: 0.5281/zenodo.56091 (accessed 21st June 2016)

19. (a) Grimme,S.; Ehrlich, S.; Georigk, L. J. Comput. Chem. 2011, 32 , 1456. (b) Grimme, S. Chem.-Eur. J.2012, 18, 9955. In testing, this correction was more robust towards choice of cut-off frequency than an alternative quasi-harmonic treatment proposed by Cramer and Truhlar: (c) Ribeiro, R. F.; Marenich, A. V.; Cramer, C. J.; Truhlar, D. G. J. Phys. Chem. B2o11, 115, 14556.

20. Legault C. Y..CYLview, 1.ob; Université de Sherbrooke: Québec, Montreal, Canada, 2009; http://www.cylview.org.

21. (a) Davies, D. L.; Donald, S.; Macgregor, S. J. Am. Chem. Soc. 2005, 127, 13754. (b) Lafrance, M.; Fagnou,K.J. Am. Chem. Soc. 20o6, 128, 16496. (c) Lafrance, M.; Rowley, C. N.; Woo, T. K.;Fagnou, K. J. Am. Chem. Soc. 2006, 128, 8754. (d) García-Cuadrado, D.; Braga, A. A. C.;Maseras, F.; Echavarren, A. M. J. Am. Chem. Soc. 20o6, 128, 1066. 
(e) Garcia-Cuadrado, D.; Mendoza, P. de;Braga,A. A. C.;Maseras, F.;Echavarren, A. M.J. Am. Chem. Soc. 2007, 129, 688o. (f) Gorelsky, S. I.; Laporte, D.; Fagnou,K. J. Am. Chem. Soc. 2008, 130, 10848. (g) Gorelsky, S. I.;Laporte, D.; Fagnou,K. J. Org. Chem. 2012, 77, 658. and for an overview of mechanistic work: (h) Laporte, D.; Fagnou,K. Chem. Lett. 2010, 39, 1118.

22. (a) Sanhueza, I. A.; Wagner, A. M.; Sanford, M. S.; Schoenebeck, F. Chem. Sci. 2013, 4, 2767. For selected reviews on computational studies of C-H activation: (b) Siegbahn, P. E. M.; Blomberg, M. R. A. Dalton Trans. 2009, 30, 5832. (c) Boutadla, Y.; Davies, D. L.; Macgregor, S. A.; Poblador-Bahamonde, A. I. Dalton Trans. 2009, 30, 5820. (d) Balcells, D.; Clot, E.; Eisenstein, O. Chem. Rev.2010, 110, 749. (e) Gorelsky, S. I. Coord. Chem. Rev.2013, 257, 153. (f) Cheng, G.-J.; Zhang, X.; Chung, L. W.; Xu, L. ; Wu, Y.-D. J. Am. Chem. Soc. 2015, 137, 1706.

23.Tanaka, D.; Romeril, P. S.; Myers, A. G. J. Am. Chem. Soc. 2005 , 127,10323

24. For chelation assisted $\mathrm{C}-\mathrm{H}$ functionalization using 8aminoquinoline, see: (a) Zaitsev, V. G.; Shabashov, D.; Daugulis, O. J. Am. Chem. Soc. 2005, 127, 13154. (b) Gou, F.-R.; Wang, X.-C.; Huo, P.-F.; Bi, H.-P.; Guan, Z.-H.; Liang, Y.-M. Org. Lett. 2009, 11, 5726. (c) Shabashov, D.; Daugulis, O. J. Am. Chem. Soc. 2010, 132, 3965. (d) Ano, Y.; Tobisu, M.; Chatani, N. J. Am. Chem. Soc. 2011, 133, 12984. (e) Ano, Y.; Tobisu, M.; Chatani, N. Org. Lett. 2011, 14, 354. (f) Tran, L. D.; Popov, I.; Daugulis, O. J. Am. Chem. Soc. 2012, 134 18237. (g) Gutekunst, W. R.; Gianatassio, R.; Baran, P. S. Angew. Chem., Int. Ed. 2012, 51, 7507. (h) Aihara, Y.; Chatani, N. Chem. Sci. 2013, 4, 664. (i) Aihara, Y.; Chatani, N. J. Am. Chem. Soc. 2013, 135, 5308. (j) Asako, S.; Ilies, L.; Nakamura, E. J. Am. Chem. Soc. 2013, 135, 17755. (k) Matsubara, T.; Asako, S.; Ilies, L.; Nakamura, E. J. Am. Chem. Soc. 2013, 136, 646. (l) Nishino, M.; Hirano, K.; Satoh, T.; Miura, M. Angew. Chem., Int. Ed. 2013, 52, 4457. (m) Rouquet, G.; Chatani, N. Chem. Sci. 2013, 4, 2201. (n) Tang, H.; Huang, X.-R.; Yao, J.; Chen, H. J. Org. Chem. 2015, 8o, 4672.

25. The data are consistent with $\mathrm{C}-\mathrm{H}$ cleavage occuring either before or after the turnover-limiting step: Simmons, E. M.; Hartwig, J. F. Angew. Chem., Int. Ed. 2012, 51, 3066.

26. (a) Hart, H.; Sedor, E. A. J. Am. Chem. Soc. 1967, 89, 2342. (b) Hoffmann, J.; Klicnar, J.; Sterba, V.; Vecera, M. Coll. Czech.Chem. Commun. 1970, 35, 1387. (c) Mueller, J. A.; Sigman, M. S. J. Am. Chem. Soc. 2003, 125, 7005.

27. The role of BINAM was also considered computationally; see SI.

28. Assuming rapid equilibration of intermediates prior to irreversible reductive elimination: Peng, Q.; Duarte, F.; Paton, R. S. Chem. Soc. Rev.2016, 45, 6093.

29. Computational pathways were located proceeding via a 3-center reductive elimination TS: (a) Pérez-Rodríguez, M.; Braga, A. A. C.; Garcia-Melchor, M.; Pérez-Temprano, M. H.;Casares, J. A.Ujaque, G.;de Lera, A. R.; Álvarez, R.; Maseras, F.; Espinet, P. J. Am. Chem. Soc. 2009, 131, 3650.

30. For analysis of an external moleculeassisted proton-shuttle TS, see:(a) involving Pd: Monot, J.; Brunel, P.; Kefalidis, C. E.; Espinosa-Jalapa, N. A.; Maron, L.; Martin-Vaca, B.; Bourissou, D. Chem. Sci. 2016, 7, 2179. (b) for other metals see: (1) Li, H.; Hall, M. B. ACS Catal. 2015, 5, 1895 .

31. For selected papers on positive charged Pd species: (a)Rauf, W.; Thompson, A. L.; Brown, J. M. Dalton Trans. 2010, 39, 10414. (b) Nishikata, T.; Abela, A. R.; Huang, S.; Lipshutz, B. H. J. Am. Chem. Soc. 2010, 132, 4978. (c) Nishikata, T.; Lipshutz, B. H. Org. Lett. 2010, 12, 1972. (c) Lin, S.; Lu, X. Org. Lett. 2010, 12, 2536.(d) Lan, Y.; Houk, K. N. J. Org. Chem. 2o11, 76, 4905. (e) Peng, Q.; Yan, H.; Zhang, X.; Wu, Y.-D.J. Org. Chem. 2012, 77, 7487.

32. (a) Proutiere, F.; Schoenebeck, F. Synlett 2012, 5, 645; (b) Plata, R. E.; Singleton, D. A. J. Am. Chem. Soc.2015, $137,3811$.

33.Additional species were considered to act as proton shuttle; BINAM- $\mathrm{H}^{+}$was superior (see SI for full details).

34. Isotope effects were evaluated according to TST applying the Bigeleisen-Mayer equation (a) Rzepa, H. S. KINISOT. 2015, DOI: 10.5281/zenodo.19272; (b) Paton, R. S. Kinisot.py , 2016, DOI: 10.5281/zenodo.60082. In testing this code gave identical results to QUIVER.
35.For a calculation of the KIE (2.66) for $\beta$-hydride elimination in palladium-catalysis, see: Hilton, M. J.; Xu, L.-P.; Norrby, P.-O.; Wu, Y.-D.; Wiest, O.; Sigman, M. S. J. Org. Chem. 2014, 79, 11841.

36.For a cautionary note, see: Lloyd-Jones, G. C.; Slatford, P. A. J. Am. Chem. Soc. 2004, 126, 2690.

37. The activation-strain, or distortion-interaction model may be appled to the TS or along the entire reaction coordinate: van Zeist, W.-J.; Bickelhaupt, F. M. Org. Biomol. Chem. 2010, 8, 3118.

38. Applications of the distortion-interaction/activation-strain models to organic and organometallic reactivity: (a) Ess, D. H.; Houk, K. N. J. Am. Chem. Soc. 2007, 129, 10646. (b) Ess, D. H.; Houk, K. N. J. Am. Chem. Soc. 20o8, 130, 10187. (c) Fernández,I.; Cossío,F.P.; Bickelhaupt,F.M. J. Org. Chem. 2011, 76, 2310; (e)Fernańdez, I.; Bickelhaupt, F.M. J. Comput. Chem. 2o12, 33, 509. (f) Gordon, C. G.; Mackey, J. L.; Jewett, J. C.; Sletten, E. M.; Houk, K. N.; Bertozzi, C. R. J. Am. Chem. Soc. 2012, 134, 9199. (g) Liang, Y.; Mackey, J. L.; Lopez, S. A.; Liu, F.; Houk, K.N. J. Am. Chem. Soc. 2012, 134, 17904. (h) Fernández, I.; Bickelhaupt, F. M.; Cossío, F. P. Chem. Eur. J. 2012, 18, 12395. (i) Lopez, S. A.; Houk, K. N. J. Org. Chem. 2013, 78, 1778. (j) Fernández, I.; Sola, M.; Bickelhaupt, F.M. Chem. Eur.J. 2013, 19, 7416. (k) Liu, F.; Paton, R. S.; Kim, S.; Liang, Y.; Houk, K. N. J. Am. Chem. Soc. 2013, 135, 15642.

39. Distortion-controlled reactivity in Pd-catalysis:Legault, C. Y.; Garcia, Y.; Merlic, C. A.; Houk, K. N. J. Am. Chem. Soc. 2007, 129, 12664. (b) Schoenebeck, F.; Houk K. N. J. Am. Chem. Soc. 2010, 132, 2496. (c) Daniels, D. S. B.; Jones, A. S.; Thompson, A. L.; Paton, R. S.; Anderson, E. A. Angew. Chem., Int. Ed. 2014, 53, 1915.

40. Paton, R. S.; Kim, S.; Ross, A. G.; Danishefsky, S. J.; Houk, K. N. Angew. Chem., Int. Ed. 2011, 50, 10366.

41.Choi, H.; Min, M.; Peng, Q.; Kang, D.; Paton, R. S.; Hong, S. Chem. Sci. 2016, 7, 3900. 


\section{TOC Graphic :}

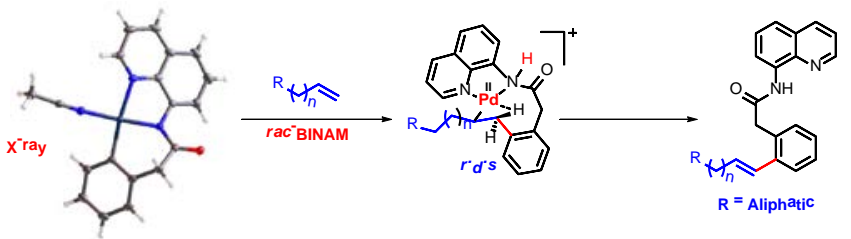

Arylpalladium
Intermediate 